IZA DP No. 8641

Do Interventions Change the Network?

A Panel Peer-Effect Model Accounting for Endogenous Network Changes

Margherita Comola

Silvia Prina

November 2014 


\title{
Do Interventions Change the Network? A Panel Peer-Effect Model Accounting for Endogenous Network Changes
}

\author{
Margherita Comola \\ PSE, Université Paris 1 Panthéon-Sorbonne \\ and IZA \\ Silvia Prina \\ Case Western Reserve University \\ Discussion Paper No. 8641 \\ November 2014 \\ IZA \\ P.O. Box 7240 \\ 53072 Bonn \\ Germany \\ Phone: +49-228-3894-0 \\ Fax: +49-228-3894-180 \\ E-mail: iza@iza.org
}

\begin{abstract}
Any opinions expressed here are those of the author(s) and not those of IZA. Research published in this series may include views on policy, but the institute itself takes no institutional policy positions. The IZA research network is committed to the IZA Guiding Principles of Research Integrity.

The Institute for the Study of Labor (IZA) in Bonn is a local and virtual international research center and a place of communication between science, politics and business. IZA is an independent nonprofit organization supported by Deutsche Post Foundation. The center is associated with the University of Bonn and offers a stimulating research environment through its international network, workshops and conferences, data service, project support, research visits and doctoral program. IZA engages in (i) original and internationally competitive research in all fields of labor economics, (ii) development of policy concepts, and (iii) dissemination of research results and concepts to the interested public.
\end{abstract}

IZA Discussion Papers often represent preliminary work and are circulated to encourage discussion. Citation of such a paper should account for its provisional character. A revised version may be available directly from the author. 
IZA Discussion Paper No. 8641

November 2014

\title{
ABSTRACT
}

\section{Do Interventions Change the Network? A Panel Peer-Effect Model Accounting for Endogenous Network Changes}

\begin{abstract}
A large literature has studied how peers affect behavior by exploiting the preexisting social network structure only. What if networks rewire in response to changes in the economic environment, such as a randomized intervention? We exploit a unique panel dataset that contains detailed information on the network of informal financial transactions before and after a field experiment that randomized access to savings accounts in Nepal. First, we show that the intervention affects the structure of the network of informal financial transactions among households. Second, we estimate a panel model of peer effects in expenditure where the network may change endogenously, and we exploit the design of the randomized intervention to instrument for the observed network change. Our results suggest that disregarding the network change would underestimate both total peer effects and the overall impact of the intervention.
\end{abstract}

JEL Classification: $\quad$ C31, D85, G2, O16

Keywords: networks, peer effects, financial access

Corresponding author:

Margherita Comola

Paris School of Economics

Université Paris 1 Panthéon-Sorbonne

106-112 Boulevard de l'Hopital

75647 Paris Cedex 13

France

E-mail: margherita.comola@psemail.eu

\footnotetext{
*We are grateful to Alfredo Burlando, Jing Cai, Carlos Chiapa, J. Paul Elhorst, Marcel Fafchamps, Bernard Fortin, Matt Jackson, Dina Pomeranz, Laura Schechter, Adam Szeidl, Susan Steiner, Mark Votruba, and seminar and conference participants at the ASSA meetings 2014, DIW-Berlin, GREQAMMarseille, IFPRI, IZA workshop on social networks, IZA-Bonn, Nanterre University, NEUDC 2012, Paris School of Economics, Toulouse School of Economics, Universidade Nova de Lisboa, University of Alicante, University of Lille, University of Oxford, and University of Pittsburgh for helpful comments. We are grateful to GONESA for collaborating on this project, and to Zach Kloos and Adam Parker for outstanding research assistance. Silvia Prina thanks the IPA-Yale University Microsavings and Payments Innovation Initiative and the Weatherhead School of Management for generous support.
} 


\section{Introduction}

A large literature has documented how peer effects through social networks affect economic behavior and help spreading new products and technologies. ${ }^{1}$ One implicit assumption grounding these studies is that pre-existing links matter for economic outcomes. This assumption is appropriate in a setting where the network is fixed or hard to change. However, it is also possible that informal networks can be rewired easily in response to changes in the economic environment, for example the introduction of a financial product. If this is the case, in order to capture the actual importance of networks in the diffusion process it is crucial to take into account how the introduction of new products and technologies may impact the pre-existing network. ${ }^{2}$

No previous empirical study has explored how interventions affect the structure of social networks, or estimated the effects of network changes on economic outcomes. Our paper intends to fill these gaps. Our contributions are twofold. First, we show that an exogenous intervention, namely an expansion in formal financial access, affects the structure of the network of informal financial transactions. Second, we use the exogenous intervention to instrument for the endogenous change in the network in a peer-effect estimation framework. This allows us to credibly evaluate the spillovers of the intervention through the network (i.e. the effects of the intervention-driven network changes on household outcomes) and the magnitude of the overall peer effect.

We take advantage of a field experiment that randomized access to savings accounts among all households living in 19 villages in Nepal. The savings account represented the first access to the formal financial system for the vast majority of the population sample. We argue that this exogenous variation in financial access may have changed the network of informal financial transactions, and that the effects could

\footnotetext{
${ }^{1}$ The list of outcomes is long and varied. See Jackson (2008), Jackson (2010), and Jackson and Yariv (2010) for an extensive review.

${ }^{2}$ In fact, anecdotal evidence and a few theoretical contributions suggest that the structure of networks evolves strategically with time. The issue of network evolution has been explored by theorists under specific assumptions (e.g. Watts 2001, Jackson and Watts 2002).
} 
be both positive and negative. On the one side, access to a savings account may allow households to accumulate a buffer stock that can be used to smooth consumption or to cope with negative shocks. Hence, it might offer a partial substitute for informal financial arrangements. As a result, informal transactions may be crowded out, reducing the level of mutual insurance and diminishing the effect of access to savings accounts on welfare (Ligon, Thomas, and Worrall 2000, Platteau 2000). On the other hand, access to savings can foster asset accumulation. Hence, households with greater resources might increase transfers to others, either because of altruism, or in fear of social sanction (Platteau 2000, Hoff and Sen 2006, Comola and Fafchamps 2010, Di Falco and Bulte 2011).

Our study exploits the combination of two unique features: the availability of network data before and after the intervention, and the within-village randomization. First, our panel dataset of all households living in 19 Nepalese villages contains detailed information on informal financial transactions (i.e. all loans and gifts given and received) before and after the randomized intervention. This allows us to exploit both the structure and the inter-temporal variation of the network to assess the effects of the intervention. Having census data we avoid making the distributional assumptions necessary for sampled dyadic observations (Chandrasekhar and Lewis 2011). Second, the within-village randomization creates exogenous variation in the treatment status of peers. This allows us to disentangle the direct treatment effect (i.e. the impact of own treatment on the individual) and the peer effect (i.e. the impact of peer characteristics and treatment status on the individual), which could not be distinguished with a village-level randomization design.

Our first contribution is to show, using household- and dyad-level regressions, that the intervention had a significant impact on the pre-existing network of informal financial transactions. Household-level regressions indicate that exogenous access to a savings account increased the number of network partners within the village. Next, we take advantage of the within-village randomization running dyadic regressions 
which account for the fact that decisions to form or sever links are two-sided. Results show that being offered the savings account increases transfers towards others, independently of the treatment status of the receivers. Overall, our findings indicate that the intervention has increased the network activity within the village, suggesting that there might be complementarity between formal savings and informal financial activities.

Having shown that the network responded to the intervention, we argue that it may be incorrect to estimate diffusion through the network using pre-intervention network data only. We set up a panel peer-effect model of household expenditure where the matrix representing village-level interactions changes endogenously over time. Our second contribution is to use the design of our exogenous intervention to generate a measure of expected network change, which we use as an instrument for the observed network change. This novel identification strategy allows us to credibly address network endogeneity in the context of our peer-effect estimation framework. Using our data we show that disregarding the network changes leads to an underestimation of both the total peer effect, and of the overall impact of the intervention. Taken together, our results provide new insights on the way we should draw inference on the effects of pre-existing links on economic outcomes.

Our paper contributes to the growing literature studying the effects of networks on economic outcomes. ${ }^{3}$ Most previous studies do not have detailed dyad-level network information. Thus, they identify the individual reference group on the basis of the respondents' social context. Exceptions are, for example, Banerjee, Duflo, Glennerster, and Kinnan (forthcoming), Oster and Thornton (2012), and Cai, de Janvry,

\footnotetext{
${ }^{3}$ Among the papers relying on a randomized intervention to identify the causal effect of social networks there are Banerjee, Chandrasekhar, Duflo, and Jackson (2013), Cai, de Janvry, and Sadoulet (forthcoming), Duflo and Saez (2003), Duflo, Kremer, and Robinson (2008), Dupas (2014), Kremer and Levy (2008), Kremer and Miguel (2007), Kling, Liebman, and Katz (2007), Oster and Thornton (2012). And, among the studies that use non-experimental methods to identify the causal effects of networks, we find Bandiera and Rasul (2006), Bertrand, Luttmer, and Mullainathan (2000), Card and Giuliano (forthcoming), Conley and Udry (2010), Foster and Rosenzweig (1995), Imberman, Kugler, and Sacerdote (2009), and Munshi (2003) and (2004).
} 
and Sadoulet (forthcoming), that, similar to our case, have detailed data on the links between households in the sample, but, differently from us, exploit pre-intervention network data only. Our results are novel in that they combines exogenous variation from a within-village randomized experiment with pre- and post-intervention network data to address network endogeneity in a credible way. To the best of our knowledge the only two papers using panel network data are Patnam (2011) and GoldsmithPinkham and Imbens (2013) who do not exploit a randomized design. ${ }^{4}$

Our study also adds to the literature estimating peer effects through network data. By exploiting the longitudinal dimension of the network data and taking differences at the household and dyad level rather than at the partners' level (Bramoullé, Djebbari and Fortin 2009, Calvó-Armengol, Patacchini, and Zenou 2009, Lee, Liu and Lin 2010), we are able to address the problem of correlated unobservables more convincingly than before.

Furthermore, our study contributes to the large literature showing how access to financial products shapes the lives of the poor. ${ }^{5}$ It also relates to the recent literature studying how access to savings accounts interacts with informal financial arrangements. ${ }^{6}$ Finally, our paper is linked to the few studies that have analyzed how formal financial access might affect sharing arrangements. The evidence is not clear

\footnotetext{
${ }^{4}$ Patnam (2011) uses a panel data of firms in India to study corporate peer effects - however, she builds her identifying instruments from observational data rather than exploiting the exogenous variation generated by a randomized experiment. Goldsmith-Pinkham and Imbens (2013) address the concern of network endogeneity by adding a strategic model of network formation into their peer effect framework. For a discussion of their model see Bramoullé (2013), Graham (2013), and Jackson (2013). Out of the peer-effect context, Fafchamps and Quinn (2012) use dyadic regressions to investigate whether exogenous group assignment fostered social links between managers of African manufacturing firms.

${ }^{5}$ See, for example, Aportela (1999), Banerjee, Duflo, Glennerster and Kinnan (forthcoming), Banerjee et al. (2013), Bruhn and Love (2009), Burgess and Pande (2005), Carvalho, Prina and Sydnor (2014), Dupas and Robinson (2013), Kaboski and Townsend (2011), Karlan and Zinman (2010), Prina (2014).

${ }^{6}$ On the one side, research has shown that savings and commitment savings products might make it easier to resist requests for sharing with friends and family (Dupas and Robinson 2013b, Brune, Giné, Goldberg and Yang 2011). On the other side, one's social network can be used as a commitment device to save actively in a savings account (Kast, Meier, and Pomeranz 2011).
} 
cut. $^{7}$

The following section describes the field experiment, the savings account, and the network data. Section 3 provides evidence that the exogenous expansion in formal financial access impacted the network of informal financial transactions. Section 4 introduces and estimates the peer-effect model with endogenous network changes and discusses the results. Section 5 concludes.

\section{Experimental Design and Background}

\subsection{Financial Institutions and the Savings Account Offered}

Formal financial access in Nepal is very limited. According to the nationally representative "Access to Financial Services Survey," conducted in 2006 by the World Bank (Ferrari, Jaffrin, and Shrestha 2007) only 20\% of Nepalese households have a bank account. Not surprisingly, access is concentrated in urban areas and among the wealthy. Thus, most households typically save informally, storing cash at home, saving in the form of durable goods and livestock, or participating to Rotating Savings and Credit Associations (ROSCAs).

In the randomized field experiment described in Prina (2014), GONESA bank gave access to savings accounts to a random sample of poor households in 19 villages surrounding Pokhara, Nepal's second largest city. The accounts have all the characteristics of any formal savings account. The enrollment procedure is simple and account holders are provided with an easy-to-use passbook savings account. The bank does not charge any opening, maintenance, or withdrawal fees and pays a $6 \%$ nominal yearly interest, similar to the average alternatives available in the Nepalese market (Nepal Rastra Bank, 2011). ${ }^{8}$ In addition, the savings account does not have a

\footnotetext{
${ }^{7}$ For example, Feigenberg, Field, and Pande (2013) and Henrich et al. (2010) find positive effects, while Binzel, Field, and Pande (2013) and Conning and Udry (2010) find negative effects.

${ }^{8}$ The International Monetary Fund Country Report for Nepal (2011) indicates a $10.5 \%$ rate of inflation during the intervention period.
} 
minimum balance requirement. ${ }^{9}$ Customers can make transactions at the local bankbranch offices in the villages, which are open twice a week for about three hours, or at the bank's main office, located in downtown Pokhara, during regular business hours. There are no additional benefits from opening an account (e.g. customers with a savings account were not eligible for credit, or lower interest rate on loans).

\subsection{Experimental Design and Data}

A first baseline survey was conducted in February 2009 in the 19 villages. All households with a female head ages of 18-55 were surveyed and the female household head was interviewed. ${ }^{10}$ This round of data contains information on households' socioeconomic characteristics and their network of informal financial transactions. Before the introduction of the savings accounts, a second baseline survey was conducted during May 2010. This survey collected information on households' socio-economic characteristics but did not collect network data. The baseline characteristics of our estimation sample are computed on the basis of these two data rounds. ${ }^{11}$

After completion of the second baseline survey, GONESA bank progressively began operating in the 19 villages between the last two weeks of May and the first week of June 2010, as follows. A pre-announced public meeting was held in each slum. Anybody in the village who wanted to attend the meeting could attend. ${ }^{12}$ At this meeting, participants were told (1) about the benefits of savings; (2) that GONESA bank was about to launch a savings account; (3) the characteristics of the savings account; (4) what the savings account could help them with and how they could use

\footnotetext{
${ }^{9}$ The money deposited in the savings account is fully liquid for withdrawal. The savings account is fully flexible and operates without any commitment to save a given amount or to save for a specific purpose.

${ }^{10}$ Female household head is defined here as the female member taking care of the household. Based on this definition, $99 \%$ of the households living in the 19 villages were surveyed by the enumerators. The female household head is also the survey respondent, and the savings account owner.

${ }^{11}$ All network and expenditure data come from the first baseline survey, while some demographic information comes from the second baseline.

${ }^{12}$ Attendance did not increase one's probability of being offered an account.
} 
it; and (5) that the savings account would only be initially offered to half of the households via a public lottery. The short public talk was given by an employee of the bank with the support of a poster and was followed by a short session of questions and answers. The main aim of the session was to provide some kind of financial literacy on the benefits of savings and savings accounts to the entire sample so that the effect of the intervention would be mainly caused by the offer of the accounts. ${ }^{13}$ Then, separate public lotteries were held in each slum to randomly assign the female household heads to either the treatment group or the control group. There was no stratification beyond village. ${ }^{14}$ Moreover, the number of individuals within each slum who would have been offered the account was set for each public lottery. In each slum, every female household head interviewed at baseline was entered in the lottery. Half of the women in each slum were assigned, through a public lottery, to the treatment, the other half to the control group. ${ }^{15}$

The women assigned to the treatment group were offered the option of opening a savings account at the local bank-branch office, ${ }^{16}$ the rest were assigned to the control group and were not given this option. ${ }^{17}$

\subsection{Sample Characteristics and Balance Check}

Table 1 shows the summary statistics of baseline characteristics, separately for treatment and control groups, for our panel estimation sample of 915 households. The last column in the table shows the $t$-statistic of two-way tests of the equality of the means across the treatment and control group and reveals that randomization generally led

\footnotetext{
${ }^{13}$ Only one public session was held in each slum. There were no individual marketing sessions.

${ }^{14}$ GONESA required that the random assignment into treatment and control groups be done publicly with balls in an urn, making stratification based on occupation or income infeasible.

${ }^{15}$ If in a village there was an odd number of women, the $50 \%+1$ woman was assigned to the treatment group.

${ }^{16}$ The offer did not have a deadline.

${ }^{17}$ For the duration of the study GONESA agreed not to open an account to any woman assigned to the control group, even if the woman applied for one. However, both women in the treatment and control group were free to open an account at any other financial institution.
} 
to balance along baseline characteristics. The women in the sample are very poor. They have on average 2.5 years of schooling, and live in households whose weekly household income average 1,500 Nepalese rupees (about \$20) and with household assets amounting to a little more than 44,000 rupees (about \$630). ${ }^{18}$ Households have on average 4.5 members with 2 children. The sample seems highly vulnerable to shocks: $42 \%$ of the households indicated having experienced a negative income shock during the month previous to the survey.

Only $15 \%$ of the households had a bank account before the introduction of the program. Given the lack of access to formal savings products, it is not surprising that most households typically save via microfinance institutions (MFIs) and ROSCAs. They also save by either investing in durable goods or livestock or by storing cash at home. Moreover, $90 \%$ of them had at least one outstanding loan (most loans are taken from ROSCAs, MFIs, and family, friends, or neighbors). Hence, households seem to rely mostly on informal financial institutions (e.g. MFIs, ROSCAs, friends, family, and neighbors) rather than on formal institutions, like banks. ${ }^{19}$ This is consistent with previous literature showing that the poor have a portfolio of transactions and financial relationships (Banerjee et al. forthcoming, Collins, Morduch, Rutherford and Ruthven 2009, Dupas and Robinson 2013a).

As shown by Prina (2014) take-up and usage rates of the savings accounts offered to the treatment group were very high. In particular, more than $84 \%$ of the treatment households offered an account opened one and used it actively, depositing an average of $8 \%$ of their baseline weekly household income almost once a week for the first year of the intervention. ${ }^{20}$ Moreover, access to the savings account did not considerably

\footnotetext{
${ }^{18}$ In 2010-2011, 70 Nepalese rupees approximately corresponded to 1 U.S. dollar. Household members earn income from multiple sources: working as agricultural or construction workers, collecting sand and stones, selling agricultural products, raising livestock and poultry, having a small shop, working as drivers, and receiving remittances, rents and pensions, among others.

${ }^{19}$ This is in line with the nationally representative survey conducted in 2006 by the World Bank. The survey shows that over two-thirds of Nepalese households had an outstanding loan from a formal or informal institution (Ferrari et al. 2007).

${ }^{20}$ Safekeeping does not appear to be common in this sample. Only 10 households (1\% of the entire sample) declare to have given any money to someone for safekeeping. Moreover, no household with
} 
increase total assets, but raised households' investments in health and education and improved their perceived financial situation. ${ }^{21}$

\subsection{Data on Informal Financial Transactions}

Detailed information on all informal network-based financial transactions was collected both in the first baseline survey and in the endline survey. The female household head was asked to give a list of people (inside or outside the village) who regularly exchange gifts and/or loans with her or other members of the household. Respondents could list as many partners as they wished. For each partner, the total amount of loans and gifts given and received in the 12 months prior to the survey was collected using four brackets: less than 1200, 1200 - 2400, 2400 - 5000 and more than 5000 rupees. $^{22}$ Special attention was devoted to accurately match the declared partners identities to sampled households and to circumvent homonymy. ${ }^{23}$

The bottom part of Table 1 contains the network descriptive statistics at baseline by treatment status. On average, households self-reported having 1.42 financial partners, 0.64 within the village ${ }^{24}$ and 0.79 outside the village. Loans seem to be more frequent than gifts: the declared number of gifts and loans exchanged with their

an account at GONESA bank reports to safekeep in the account money that belongs to someone else. Hence, while it is possible that treatment households deposited someone else's money into their account, the data do not appear to support this.

${ }^{21}$ See Prina (2014) for a detailed analysis of the effects of providing access to a savings account on assets accumulation and household welfare.

${ }^{22}$ We also collected information on the exact amount and the reason of those transfers which took place within the last month. However, very few respondents reported an exact value for transfers in the month prior. Hence in our main estimations we use the ordinal measure that spans a longer period and may incorporate multiple transactions.

${ }^{23}$ At the end of each interview the enumerator used an updated village roster to determine, jointly with the respondent, the household identity code of the mentioned partners. Thus, the partners' unique identifiers were coded into the questionnaire while in the field, not during the data cleaning process.

${ }^{24}$ This is the number partners that the respondent declares within the village, which do not correspond precisely to the total number of links within the village that we use in our estimation (0.72 on average, as reported in the Appendix Table A1) because a few self-reported names could not be traced to identities in the roster, and because we take the maximum report out of the two parts involved whenever discrepancies arise (as explained in Section 3). 
partners is 0.79 and 1.90 respectively. Overall, at baseline, treatment and comparison groups are well balanced along network characteristics. Finally, Table 2 reports the attrition regressions for the sample of 1,009 households who completed both baseline surveys. Results show that the probability of completing the endline survey does not seem to depend either on the treatment or on the network characteristics.

Two caveats are in order. First, as we consider a field experiment that randomized financial access, our study analyzes the network of informal financial transactions. One's social network however, spans many dimensions of social interactions other than the financial ones. Nevertheless, since all social dimensions are likely to be intertwined, the change in the network of informal financial transactions is likely to provide a lower bound for the overall peer effect which flows through one's multiple social dimensions, and may also spill over to other types of social relationships that are out of the scope of our analysis. Second, our study uses actual (rather than hypothetical) transfer data, (i.e. we asked households 'who did you exchange loans/gifts with?' rather than 'who would you exchange loans/gifts with, in case of need?'). Actual transfer data are advantageous in a context of financial exchanges, mainly because they limit the amount of measurement error due to respondents' subjective

evaluation. Hence, our results should be interpreted in light of the type of network data we elicited, that is, in terms of actual transactions occurred rather than in terms of the underlying network of support that can be triggered in case of need.

\section{The Impact of the Intervention on the Network}

Next, we study whether the exogenous expansion in formal financial access has affected the network of informal financial transactions. 


\subsection{Notation and Network Statistics}

Vectors are denoted with bold lower-case letters and matrices with bold capital letters. If $\mathbf{A}$ is a $n \times m$ matrix, we write $\mathbf{A}_{[i j]} \equiv a_{i j}$ to indicate its $(i, j)^{t h}$ entry. If $\mathbf{b}$ is a $n \times 1$ vector, we write $\mathbf{b}_{[i]} \equiv b_{i}$ to indicate its $i^{\text {th }}$ row. When a matrix or a vector is indexed by time, this is indicated with a superscript to avoid confusion with the entry notation, e.g. we write $a_{i j}^{t}$ and $\mathbf{A}^{t}$, where $t=0$ represents the baseline survey and $t=1$ represents the endline survey.

In our analysis we use the within-village network data to generate two interaction matrices: the directed ordinal matrix $\mathbf{C}^{t}$ and the undirected binary matrix $\mathbf{G}^{t}$. Both matrices are block-diagonal because, by construction, only transfers within the same village are allowed. ${ }^{25}$ The matrix $\mathbf{C}^{t}$ represents the directed ordinal network at time $t$ : starting from our set of $n$ sampled households $(1, \ldots, n)$ for each pair ('dyad') of households $i j$ the matrix's $(i, j)^{t h}$ entry $c_{i j}^{t}$ classifies the transfer from $i$ to $j$ at time $t$ into a five-category scale: 0 (no transfer), 1 (less than 1,200 rupees), 2 (1,2002,400 rupees), 3 (2,400-5,000 rupees), and 4 (more than 5,000 rupees). No self link is allowed, i.e. $c_{i i}^{t}=0$. Note that the matrix represents within-households (rather than within individuals) transfers: hence, $c_{i j}^{t}=1$ if a member of household $i$ has given a loan/gift to member of $j$. Since directed transfers do not need to be symmetric, both dyads $i j$ and $j i$ are included in the estimation sample. ${ }^{26}$ Depending on the specification, transfers in $\mathbf{C}^{t}$ are defined in terms of: loans only, gifts only, loans or gifts.

\footnotetext{
${ }^{25}$ The declared partners who live outside the village are omitted from the analysis since they were not part of the sample considered in the randomized experiment. Hence, we cannot apply our methodology.

${ }^{26}$ For each directed observation $c_{i j}^{t}$ we have two reports: how much $i$ declares to have given to $j$ and how much $j$ declares to have received from $i$. In principle, the answers to these questions should be the same, in practice they often are not. This is a common problem in the empirical literature using self-reported link data. The standard solution is to assume that a link exists if it is reported by either $i$ or $j$ or a combination of the two (De Weerdt 2004, De Weerdt and Fafchamps 2011, Fafchamps and Lund 2003, Liu, Patacchini, Zenou, and Lee 2012, Banerjee et al. 2013). Following this literature, whenever discrepancies arise, we take the maximum report out of the two parts involved. This is equivalent to assuming that discrepancies between survey answers correspond to under-reporting, perhaps as a result of omission mistakes.
} 
$\mathbf{G}^{t}$ is the interaction matrix we use for the peer-effect regressions in Section 4 and represents binary undirected transfers: the $(i, j)^{t h}$ entry $g_{i j}^{t}=g_{j i}^{t}$ equals one if $c_{i j}^{t}>0$ or $c_{j i}^{t}>0$, where transfers are defined in terms of loans or gifts. Figures 1 and 2 represent $\mathbf{G}^{0}$ and $\mathbf{G}^{1}$ (that is, the network of binary undirected transfers for baseline and endline, respectively) for households with at least one link. The average number of links is 0.72 for both baseline and endline and, as the figures display, these networks are sparse into small groups which display virtually no clustering. Also, the network has undergone a reshuffle between baseline and endline: out of the 328 links observed at baseline in $\mathbf{G}^{0}$ only $73(22 \%)$ were actually the same in $\mathbf{G}^{1}$ while 255 $(78 \%)$ were not. On the other end, at endline we observe 256 newly-formed links.

\subsection{Household-level Regressions}

We first consider the household as the unit of observation to present a set of reducedform results on the effect of the intervention on the level of informal financial transactions. Let network $k_{i}^{1}$ be a proxy for the intensity of the network-based activity of household $i=1, \ldots, n$ at endline, i.e. at $t=1$. Let $i t t_{i}$ be the intent-to-treat dummy, which takes value one if $i$ was offered a savings account. Let $x_{i}^{0}$ represent the demographic characteristics of $i$ at baseline, i.e. at $t=0$. We run the following household-level intent-to-treat linear regression:

$$
\text { network }_{i}^{1}=\beta_{0}+\beta_{1} i t t_{i}+\beta_{2} x_{i}^{0}+\lambda_{v}+\epsilon_{i}^{1}
$$

where $\lambda_{v}$ represents village-level fixed effects and $\epsilon_{i}^{1}$ is the exogenous error term, clustered at the village level to accommodate for arbitrary patterns of residual correlations. Because of the randomized design of the intervention, $i t t_{i}$ is a first proxy for the effects of the treatment status on the level of network activity.

In Table 3 we estimate equation (1) taking as dependent variable the following network statistics: number of partners within the village (columns 1-3) and number 
of partners outside the village (columns 4-6). ${ }^{27}$ The set of socio-demographic controls (at baseline), which will remain the same throughout the paper, include: the age of the female household head, a dummy which takes value one if the female household head has no formal education, her marital status dummies (married and single dummies, where the omitted category is separated/widowed/abandoned), household size, number of children less than 16 years of age, and shock dummies (death, livestock loss, land loss, and bad harvest). The descriptive statistics of all household-level variables are reported in Appendix Table A1.

Results show that having been offered the savings account increases significantly the number of partners within the village a year after the intervention. For the number of declared partners outside the village we do not find any statistically significant direct intent-to-treat effect. Overall, these results provide some preliminary evidence that the effects of the intervention spilled over to the network of informal financial transactions.

\subsection{Dyad-level Regressions}

Household-level regressions do not take into account the fact that formation and severance of links are dyadic decisions, where one's outcome also depends on current and potential partners: by providing access to savings accounts to half of the households in the villages, the intervention did not only affect treatment households, but also the control households who were connected or could potentially be connected to them. In what follows we exploit the dyadic nature of our data, which allow us to disentangle the effect of the treatment status of giver and receiver. We take the directed within-village dyad as the unit of observation, for a total of 56,308 observations. The

\footnotetext{
27 To be consistent with what follows, in these regressions, we consider the partners within the village whose identity was traced to respondents in the roster. As for the partners outside the village, we have to rely on self-reported data.
} 
descriptive statistics for the dyadic sample are reported in Appendix Table A2.

First, we explore the effect of the intervention on the magnitude of the dyadic transfers within the village, running the following linear regression: ${ }^{28}$

$$
c_{i j}^{1}=\beta_{0}+\beta_{1} i t t_{i}+\beta_{2} i t t_{j}+\beta_{3} x_{i}^{0}+\beta_{4} x_{j}^{0}+\lambda_{v}+\epsilon_{i j}^{1}
$$

where the directed dependent variable $c_{i j}^{1}$ is the $(i, j)^{t h}$ entry of $\mathbf{C}^{1}$ and classifies the transfer at endline from $i$ to $j$ as: 0 (no transfer), 1 (less than 1,200 rupees), 2 (1,200-2,400 rupees), 3 (2,400-5,000 rupees), and 4 (more than 5,000 rupees). The two dummies of interest are the treatment status of the potential giver and receiver, $i t t_{i}$ and $i t t_{j}$ respectively. The specification also includes the controls at baseline for giver and receiver $\left(x_{i}^{0}\right.$ and $x_{j}^{0}$ respectively) and village fixed effects $\lambda_{v}$. Standard errors are clustered at the village level. ${ }^{29}$

Estimation results reported in Table 4 are based on three different definitions of transfers: gifts only, loans only, and loans or gifts. Results show that the treatment status of the giver, $i t t_{i}$, increases the magnitude of loans (and total transfers), but has no effect on gifts. This means that the households who were offered the savings account ceteris paribus increased loans to others. The estimated coefficients may seem small in absolute terms. However, they are large compared to the mean of the dependent variables (reported at the bottom of the table), which is naturally small since dyadic datasets include all possible within-village directed pairs. Interestingly, the treatment status of the receiver, $i t t_{j}$, does not appear significant, suggesting that the increase in informal transactions is driven by the giver's side: those who were

\footnotetext{
${ }^{28}$ We prefer linear estimates over logit and probit regressions because, for such an exiguous number of non-zero dependent variables, in non-linear estimates the combination of controls and village dummies may predict the binary outcome perfectly. Thus, many observations would get dropped (especially when considering gifts).

${ }^{29}$ In presence of many unlinked populations, clustering is the preferable solution for dyadic network data as it allows for arbitrary cross-observation dependance (Barr, Dekker and Fafchamps 2012, Arcand and Fafchamps 2012). In our context, clustering may also address the negative correlation arising if households were financially saturated (i.e. if having one link would discourage an household to form other links).
} 
offered the savings account increased their loans towards other households, regardless of the treatment status of their partners. Overall, the results shown in Table 4 suggest complementarity between formal savings and informal network-based financial activities.

To fully exploit the longitudinal dimension of our data, we also run the panel version of the directed intent-to-treat regression of equation (2), represented by the equation:

$$
c_{i j}^{t}=\beta_{0}+\delta_{0}(t=1)+\beta_{1} i t t_{i}+\beta_{2} i t t_{j}+\beta_{3} i t t_{i} * i t t_{j}+\beta_{4} x_{i}^{t}+\beta_{5} x_{j}^{t}+\alpha_{i j}+\epsilon_{i j}^{t}
$$

where the ordinal dependent variable $c_{i j}^{t}$ is defined as before, $\delta_{0}(t=1)$ represents a time-trend, and $\alpha_{i j}$ represents the dyad-level fixed effect. As we have a two-period panel, this specification corresponds to a first-difference estimation. The advantage of this specification over equation (2) is that the dyad-level dummy absorbs all the time-invariant dyad-specific characteristics, thus alleviating the concern of assortative matching along unobservables.

Results from estimating equation (3) are reported in Table 5. In columns (3), (6), and (9) we also include the interaction term $i t t_{i} * i t t_{j}$ between giver and receiver treatment status. The estimates in Table 5 confirm those shown in Table 4, supporting the previous finding that the giver's treatment status positively affect the amount of loans given.

Finally, we also present similar results for the binary matrix of undirected transfers $\mathbf{G}^{t}$. This corresponds to the most general empirical specification at the dyadic level which investigates whether the probability of a non-zero transfer between households $i$ and $j$ is affected by their treatment status. We run the following linear panel regression: 


$$
\begin{aligned}
g_{i j}^{t} & =\beta_{0}+\delta_{0}(t=1)+\beta_{1} \cdot D\left(i_{t} t_{i}=1 \text { or }_{i t t_{j}}=1\right) \\
& +\beta_{2} \cdot D\left(i t t_{i}=1 \text { and }_{i t t_{j}}=1\right)+\beta_{4}\left|x_{i}^{t}-x_{j}^{t}\right|+\alpha_{i j}+\epsilon_{i j}^{t}
\end{aligned}
$$

where the binary dependent variable $g_{i j}^{t}$ equals one if there was a transfer (loan or gift) at time $t$ between $i$ and $j$ (i.e. from $i$ to $j$ or from $j$ to $i$ ). As the unit of observation is the undirected dyad (i.e. $g_{i j}^{t}=g_{j i}^{t}$ ), the controls must also enter in a undirected fashion. Thus, treatment status is captured by two binary indicators which take value one if $\left(i t t_{i}=1 \mathrm{or}_{i t t}=1\right)$ and if $\left(i t t_{i}=1\right.$ and $\left._{j} t t_{j}=1\right)$, respectively. Also other controls are computed as the absolute difference between $x_{i}^{t}$ and $x_{j}^{t}$, as it is customary in the literature on undirected dyadic regressions. The results reported in Table 6 reconfirm the findings of Tables 4 and 5. As the coefficients for both $D\left(i t t_{i}=1\right.$ or $\left.i t t_{j}=1\right)$ and $D\left(i t t_{i}=1\right.$ and $\left.i t t_{j}=1\right)$ are significant and of similar magnitude, we conclude that the probability of a non-zero transfer between $i$ and $j$ increases if at least one of them is offered the savings account. These results will be a building block for our instrumentation strategy discussed in subsection 4.3.

\subsection{Discussion}

Overall, being offered access to a savings account increases loans and overall transfers to financial partners within the village. There are many (complementary) hypotheses that could explain these results, and that we try to test. ${ }^{30}$

First, treatment households might face more redistributive pressure. We test whether households who had stronger beliefs about network support at baseline and were offered a savings account were more likely to give out loans and/or gifts afterward. ${ }^{31}$ This does not appear to be the case.

\footnotetext{
${ }^{30}$ Regressions results in this section are not shown, but are available upon request.

${ }^{31}$ The questions used to measure network support and beliefs were: (a) 'If I ask someone (a relative, friend or neighbor) for money, and she has some, the she should help me'; (b) 'If I start saving money, people will think I'm rich and will ask me for more money'; (c) 'It is difficult to save because when I have some money set aside, my relatives/friends/neighbors ask for it'.
} 
A second potential explanation could be that treatment women, now that have access to a savings account, feel more empowered so that they transfer more. We do not have data on women bargaining power at endline. Thus, we proxy women bargaining power with the difference in education between husband and wife. The coefficient of the interaction between treatment dummy and women empowerment proxy at baseline however, is not statistically significant.

A related hypothesis is that empowered women now manage their finances more independently than before and are thus capable of transferring outside the household those funds that were flowing within the households before (e.g. forced transfers to the husband). This hypothesis would be consistent with the evidence that net transfers between households increased at the village level. Unfortunately we cannot test this hypothesis as we did non collect information on within-household transfers.

An additional explanation could be that treatment households who were better off at baseline make more transfers. We run dyadic regression of transfer variables against treatment status, various proxies for wealth (total assets at baseline, income at baseline, and an index of financial inclusion), their interactions, and controls. Results show that treatment households with a higher level of total assets at baseline are more likely to give out loans and transfers (independently of the treatment status of the receiver). Similarly, treatment households with a higher level of income at baseline are more likely to give gifts to others. Finally, treatment households who had already access at baseline to the formal and semi-formal financial system are more likely to give loans to others. Overall, while there might be additional explanations for the results shown in Tables 4 and 5 , it seems to be that the more wealth, income and financial inclusion treatment households have at baseline, the more transfers they make to others. 


\section{The Spillover Effects of the Intervention}

Having shown that the exogenous expansion in formal financial access affected the network, we argue that it may be misleading to evaluate whether informal networks help diffusing the effect of the intervention using pre-intervention network data only. Doing so we might miss a possibly important channel through which the intervention impacts individual outcomes: the spillover effect of the intervention through the network, i.e. the effect of the intervention-driven network changes on household outcomes.

Next, we show how to incorporate these spillovers within a model of peer effects. Most previous peer-effect studies exploiting the network structure of social interactions have used network data collected at one point in time (e.g. Bramoullé et al. 2009, Calvó-Armengol et al. 2009). Thus, the validity of their results relies on the assumption that the network structure is not affected by the variables of interest. Challenging this assumption is the scope of this section. First, we introduce the benchmark model with time-invariant interaction matrix, and later we discuss a peer-effect model which allows the interaction matrix to vary endogenously. Then, we show that disregarding the network changes we obtain biased peer-effect estimates and we underestimate the overall impact of the intervention.

\subsection{A Peer-effect Model with Static Network}

Define $\mathbf{y}^{t}$ as the $n \times 1$ vector representing the household outcome of interest at time $t$, which in our empirical illustration is the household's total non-food expenditure in natural logs. ${ }^{32}$ Recall that $\mathbf{G}^{t}$ represents the undirected binary $n \times n$ matrix of social interactions, and that itt denotes the intent-to-treat vector. Call $\boldsymbol{\epsilon}^{t}$ the vector of disturbances, and $\iota$ a $n \times 1$ vector of ones. We use $\Delta$ to denote a change in a given

\footnotetext{
${ }^{32}$ Total non-food expenditure is calculated as the sum of all expenditure in the past month on health, education, clothes and footwear, personal care items, festivals and ceremonies, repairs and home maintenance.
} 
variable from baseline to endline. ${ }^{33}$ Following Bramoullé et al. (2009) our peer-effect model for period $t=0$ can be written in matricial form as: ${ }^{34}$

$$
\mathbf{y}^{0}=\alpha_{0} \iota+\beta \mathbf{G}^{0} \mathbf{y}^{0}+\boldsymbol{\mu}+\boldsymbol{\epsilon}^{0}
$$

where $\boldsymbol{\mu}$ represent the household fixed effect. The expenditure of household $i$ is assumed to depend linearly on the total expenditure of its partners: $\mathbf{G}^{0} \mathbf{y}_{[i]}^{0}=\sum_{k=1}^{n} g_{i k}^{0}$. $y_{k}^{0}$ where $g_{i k}^{0}$ is the $(i, k)^{t h}$ entry of $\mathbf{G}^{0}{ }^{35} \mathbf{G}^{0} \mathbf{y}^{0}$ is usually referred to as the first lag of the dependent variable, and its coefficient $\beta$ represents the strength of the peer effect. ${ }^{36}$ The corresponding equation for $t=1$ is:

$$
\mathbf{y}^{1}=\left(\alpha_{0}+\alpha\right) \boldsymbol{\iota}+\beta \mathbf{G}^{1} \mathbf{y}^{1}+\gamma \mathbf{i t t}+\delta \mathbf{G}^{1} \mathbf{i t t}+\boldsymbol{\mu}+\boldsymbol{\epsilon}^{1}
$$

where we add the intercept coefficient $\alpha$ to allow for time trends, and we introduce two additional terms: itt and $\mathbf{G}^{1} \mathbf{i t t}$. The intent-to-treat vector, itt, represents the direct effect of one's treatment status. The first lag of the intent-to-treat vector, $\mathbf{G}^{1}$ itt, represents the number of one's partners at endline that was offered the savings account. This term captures any effect of the treatment status of one's partners which does not transit through their expenditure. ${ }^{37}$

\footnotetext{
${ }^{33}$ For instance, $\Delta \mathbf{y}=\mathbf{y}^{1}-\mathbf{y}^{0}$ represents the change in total non-food expenditure from baseline to endline. Note that the term is positive when $\mathbf{y}$ has increased with time.

${ }^{34}$ Most previous studies on peer effects have used data where individuals are partitioned into mutually-exclusive fully-overlapped reference groups (e.g. all children belonging to the same class). Doing so, they assume that individuals are equally affected by all other individuals belonging to their group and by nobody outside their group. Our model belongs to the group of peer-effect models where the interaction is structured through social networks, such that the reference group has individual-level variation: if $i$ and $j$ are connected and $j$ and $k$ are connected, it does not necessarily imply that $i$ and $k$ are also connected. Bramoullé et al. (2009) show how to estimate such models by providing the identification conditions and the moment restrictions we use in this paper.

${ }^{35}$ We adopt a linear-in-sums identification strategy by modeling the individual outcome as a linear function of the sum of one's partners' outcome (Liu et al. 2012), consistently with the idea of a multiplier effect in credit and expenditure decisions. However whether we choose the sum versus the average of partners' outcomes has very little practical relevance in our context since the mean number of links is smaller than one.

${ }^{36}$ In analogy with time series econometrics, it is customary to assume that the process is stationary, i.e. that $\beta<|1|$ (Kelejian and Prucha 1998).

${ }^{37}$ We present here the most general version of the model - however, results remain the same if we impose the exclusion restriction that partner's treatment status has no direct effect other than
} 
Let us first assume that the interaction matrix is non-stochastic, i.e. has a fixed and known structure: $\Delta \mathbf{G}=0$. Hence, subtracting (5) from (6), we obtain the firstdifference estimating equation

$$
\Delta \mathbf{y}=\alpha \boldsymbol{\iota}+\beta \mathbf{p e}_{A}+\gamma \mathbf{i t t}+\delta \mathbf{G}^{0} \mathbf{i t t}+\Delta \boldsymbol{\epsilon}
$$

where the peer-effect term that we write $\mathbf{p e}_{A} \equiv \mathrm{G}^{0} \Delta \mathbf{y}$ represents the total expenditure change of one's partners. ${ }^{38}$ We refer to equation $(7)$ as to the "peer-effect model with static network." This model exploits the full structure of the network data at baseline to identify the peer effect through non-overlapping reference groups. This feature, combined with the fact that our randomization is within villages (rather than across villages), allows us to disentangle the effect of one's treatment status and one's

partners treatment status. For the sake of estimation we assume that disturbances $\Delta \boldsymbol{\epsilon}$ are exogenous, heteroskedastic, and arbitrarily correlated within villages. ${ }^{39}$

\subsection{A Peer-effect Model with Endogenous Network}

The validity of the model of equation (7) relies on the assumption that the interaction matrix has a fixed and known structure, which in our context is misleading as we have shown in Section 3. In what follows we introduce a panel peer-effect model where the interaction matrix is stochastic and changes endogenously: $\Delta \mathbf{G} \neq 0$. In order to write the estimating equation, note first that the total change in partners' expenditure can be written as:

$$
\mathbf{G}^{1} \mathbf{y}^{1}-\mathrm{G}^{0} \mathbf{y}^{0}=\mathbf{G}^{0} \Delta \mathbf{y}+\Delta \mathbf{G} \mathbf{y}^{0}+\Delta \mathbf{G} \Delta \mathbf{y}
$$

through partner's outcome (i.e. dropping $\mathbf{G}^{1} \mathbf{i t t}$ ).

${ }^{38}$ In the terminology of Manski (1993), $\mathbf{G}^{0} \mathbf{i t t}$ is called the exogenous social effect, and $\mathbf{p e}_{A}$ the endogenous social effect.

${ }^{39}$ Note that the Generalized 2SLS strategy first proposed by Kelejian and Prucha (1998) and used by Kelejian and Piras (2014) reduces to standard 2SLS whenever disturbances are not spatially correlated. 
where for a given household $\mathbf{G}^{0} \Delta \mathbf{y}$ represents the change in its partners' total expenditure keeping partners constant, $\Delta \mathbf{G} \mathbf{y}^{0}$ represents the change in its partners' total expenditure keeping expenditure constant, and $\Delta \mathbf{G} \Delta \mathbf{y}$ accounts for the combined effect of the expenditure change and the network change. ${ }^{40}$ In order to improve the readability, in what follows we write $\mathbf{p e}_{A} \equiv \mathbf{G}^{0} \Delta \mathbf{y}, \mathbf{p e}_{B} \equiv \Delta \mathbf{G ~}^{0}$ and $\mathbf{p e}_{C} \equiv \Delta \mathbf{G} \Delta \mathbf{y}$, respectively. Also, note that we can write $\mathbf{G}^{1} \mathbf{i t t}=\mathbf{G}^{0} \mathbf{i t t}+\Delta \mathbf{G} \mathbf{i t t}$, where $\Delta \mathrm{G}$ itt represents the change in the number of partners that was offered the savings account. Subtracting (5) from (6) we obtain the first-difference estimating equation:

$$
\Delta \mathbf{y}=\alpha \boldsymbol{\iota}+\beta_{1} \mathbf{p} \mathbf{e}_{A}+\beta_{2} \mathbf{p} \mathbf{e}_{B}+\beta_{3} \mathbf{p} \mathbf{e}_{C}+\gamma \mathbf{i t t}+\delta_{1} \mathbf{G}^{0} \mathbf{i t t}+\delta_{2} \Delta \mathbf{G} \mathbf{i t t}+\Delta \epsilon
$$

We refer to this model as a "peer-effect model with endogenous network." Note how the peer-effect model with static network of equation (7) is nested into the model with endogenous network of equation (9). The first peer-effect term $\mathbf{p e}_{A}$, which appears in both models, represents the total expenditure change of one's baseline partners. The other two peer-effect terms, which only appear in equation (9), account for the network change. In particular, $\mathbf{p e}_{B}$ represents the network changes in terms of baseline expenditure: for a given household, $\mathbf{p e}_{B}$ is positive if at baseline the total expenditure of its new partners was higher than the total expenditure of its old partners. This term is positive whenever the household formed new links with those partners who were already better endowed ex ante. And, $\mathbf{p e}_{C}$ accounts for the combined effect of the expenditure change and the network change: for a given household, $\mathbf{p e}_{C}$ is positive if the total expenditure of its new partners has increased more than the total expenditure of its old partners from baseline to endline. This term is positive whenever the household formed new links with those partners whose expenditure increased the most. The three peer-effect terms are correlated: $\mathbf{p e}_{C}$ is

\footnotetext{
${ }^{40}$ This is close in spirit to the Oaxaca (1973) decomposition, which aims at splitting earnings gaps into differences in characteristics and in performances.
} 
likely to be negatively correlated with $\mathbf{p} \mathbf{e}_{A}$ and $\mathbf{p} \mathbf{e}_{B},{ }^{41}$ while the correlation between $\mathbf{p e}_{A}$ and $\mathbf{p e}_{B}$ depends on the specific network structure. Thus, disregarding the spillover effects of the intervention through the network may not only lead to biased estimates of $\mathbf{p e}_{A}$ in equation (7), but also to incorrect estimates of the total effect of the intervention on the outcome of interest. ${ }^{42}$

\subsection{Addressing Endogeneity}

We now discuss three different sources of endogeneity which may arise when estimating equations (7) and (9) and our empirical strategy to address them.

\subsubsection{Correlated Unobservables}

The first endogeneity problem stems from the fact that linked individuals tend to behave similarly because they are alike to start with (Manski 1993). By exploiting the panel dimension of our data, we are able to address the issue of endogeneity from correlated unobservables. Bramoullé et al. (2009) show that, in analogy with linear panel data, correlated unobservables can be treated as fixed effects and equation (7) can be consistently estimated as long as the interaction matrix is conditionally exogenous (i.e. strictly exogenous conditional on the model's fixed effects). However, since they use cross-sectional data, their within transformation is implemented at the partner level (i.e. they express the model in deviation from the individual's partners). ${ }^{43}$ Therefore their identification strategy is valid as long as all correlated unobservables

\footnotetext{
${ }^{41}$ This is true by construction if the process is stationary.

${ }^{42}$ Formally, if the network change is driven by the intervention, the total marginal effect of the intervention on expenditure (which includes all direct and indirect effects) is given by the matrix of cross derivatives $\frac{\delta E(\Delta \mathbf{y})}{\delta \mathbf{i t t}_{k}}$. This is based on the reduced form of the peer-effect model with endogenous network $\Delta \mathbf{y}=\left(I-\beta_{1} \mathbf{W}^{0}-\beta_{3} \Delta \mathbf{W}\right)^{-1}\left[\alpha \boldsymbol{\iota}+\beta_{2} \Delta \mathbf{W} \mathbf{y}^{0}+\gamma \mathbf{i t t}+\delta_{1} \mathbf{W}^{0} \mathbf{i t t}+\delta_{2} \Delta \mathbf{W}\right.$ itt $]$, which is an augmented version of the static-model reduced form $\Delta \mathbf{y}=\left(1-\beta_{1} \mathbf{W}^{0}\right)^{-1}\left[\alpha \boldsymbol{\iota}+\gamma \mathbf{i t t}+\delta_{1} \mathbf{W}^{0} \mathbf{i t t}\right]$ and also incorporates the intervention spillovers.

${ }^{43} \mathrm{~A}$ similar result holds for the within transformation implemented at the network level (which corresponds to the village level in our illustration), to which this discussion applies as well.
} 
affecting both household outcome and link formation are common to all connected partners. The panel nature of our data allows us to implement a within transformation at the household level by estimating all equations in first differences. Doing so addresses these endogeneity concerns more convincingly as long as one believes that all confounding unobservables (such as homophily between partners in risk attitude, savings and spending behavior, and financial literacy) are time-invariant within the duration of our study. ${ }^{44}$

\subsubsection{Simultaneity}

Because of the model's simultaneity (i.e. the outcomes of the household and its partners are jointly determined), we have a second problem of endogeneity which affects both the static network model and the endogenous network model: the term $\Delta \mathbf{y}$ (which appears in $\mathbf{p} \mathbf{e}_{A}$ and $\mathbf{p e}_{C}$ ) is correlated with the disturbance vector $\Delta \boldsymbol{\epsilon}$, which may invalidate OLS inference. As shown by Bramoullé et al. (2009), the equation can be consistently estimated with 2SLS using as instruments "lagged" partners characteristics (that is, the exogenous attributes of the partners of one's partners) as long as the interaction matrix is either non-stochastic (as in equation 7) or stochastic but conditionally exogenous (as in equation 9) and it is not partitioned into mutuallyexclusive fully-overlapped reference groups, which is not our case. ${ }^{45}$ This instrumentation strategy is standard in spatial and network interaction models (Bramoullé et al. 2009, Calvò-Armengol et al. 2009, Drukker, Egger and Prucha 2013, Kelejian and Prucha 1998, Patacchini and Zenou 2012). We use two exogenous characteristics of lagged partners at baseline as identifying instruments for the change in total

\footnotetext{
${ }^{44}$ Note that this within transformation also mitigates the concerns related to the existence of many isolated households (i.e. households who have no links, either at baseline or at endline or both) who may be different from connected households along many relevant yet unobserved dimensions.

${ }^{45}$ Said otherwise, as long as the interaction matrix is exogenous and there are households who are excluded from one's reference group but are included in the reference group of her partners, their exogenous characteristics may affect one's outcome only through her partners and thus are a natural set of instruments to overcome the reflection problem (Manski 1993).
} 
expenditure $\Delta \mathbf{y}$ : the number of partners' partners at baseline that was offered the savings account (call it $\mathbf{i v}_{1}$ ) and the baseline expenditure of those partners' partners at baseline who were offered the savings account (call it $\left.\mathbf{i v}_{2}\right) .{ }^{46,47}$

\subsubsection{Endogenous Network}

The third concern relates to the network change, which is also potentially endogenous. This affects regressors $\mathbf{p e}_{B}, \mathbf{p e}_{C}$ and $\Delta \mathbf{G}$ itt in equation (9) as they are built on $\Delta \mathbf{G}$. We address this issue by exploiting the randomized structure of our intervention. In Section 3 we showed that the intervention affected the structure of the network of informal financial transactions within the villages. Building on these results we use the expected change in the network following the intervention as an instrument for the observed change in the network. The consistency of the 2SLS estimator in presence of endogenous weighting matrix is demonstrated by Kelejian and Piras (2014) in the context of spatial panel data. We apply this IV procedure to network interaction data and proceed as follows. Since the interaction matrix used in the peer-effect regressions is binary and undirected, we take the most general specification of equation (4) (Table 6, column 2) and generate, for each dyad, a linear fitted probability of being connected $\hat{g}_{i j}^{t}=\hat{g}_{j i}^{t}$, based on the exogenous treatment status of the two households involved. This defines an undirected matrix $\hat{\mathbf{G}}^{t}$ whose entries, $\hat{\mathbf{G}}_{[i j]}^{t} \equiv \hat{g}_{i j}^{t}$, are fitted probabilities. The originality of our empirical strategy relies on the fact that we use $\hat{\mathbf{G}}^{t}$ to generate the following five instruments:

- $\mathbf{i v}_{3} \equiv \hat{\mathbf{G}}^{0} \mathbf{y}^{0}$ corresponds to the total $\mathbf{y}^{0}$ of expected baseline partners. For household $i$ we compute $\mathbf{i v}_{3[i]}=\sum_{j} \mathbf{y}_{j}^{0} \hat{g}_{i j}^{0}$, i.e. we weight the $\mathbf{y}_{[j]}^{0}$ of each potential partner $j$ with his fitted probability of being connected with $i$;

\footnotetext{
${ }^{46}$ The count of the partners of one's partners does not include the household itself.

${ }^{47}$ For instance, let us imagine a network composed of six agents $\{a, b, c, d, e, f\}$ such that there are 4 links at baseline $g_{a c}^{0}=g_{f c}^{0}=g_{e c}^{0}=g_{d b}^{0}=1$ (and zero elsewhere) and only three agents $\{b, e, f\}$ are offered the savings account. The only partner of $a$ is $c$ and $c$ 's partners are $e$ and $f$, who were both offered the savings account. Thus, we get $\mathbf{i} \mathbf{v}_{\mathbf{1}[\mathrm{a}]}=2$ and $\mathbf{i} \mathbf{v}_{\mathbf{2}[\mathbf{a}]}=\mathbf{y}_{\mathbf{e}}{ }^{0}+\mathbf{y}_{\mathbf{f}}{ }^{0}$.
} 
- $\mathbf{i v}_{4} \equiv \hat{\mathbf{G}}^{1} \mathbf{y}^{0}$ corresponds to the total $\mathbf{y}^{0}$ of expected endline partners. We compute it as above: $\mathbf{i v}_{4[i]}=\sum_{j} \mathbf{y}_{j}^{0} \hat{g}_{i j}^{1}$;

- $\mathbf{i v}_{5} \equiv \hat{\mathbf{G}}^{1} \mathbf{i t t}$ corresponds to the expected number of endline partners who got offered the treatment, i.e. $\mathbf{i v}_{5[i]}=\sum_{j} \mathbf{i t t}_{j} \hat{g}_{i j}^{1}$;

- $\mathbf{i v}_{6}$ represents the total expected increase in $\mathbf{y}^{0}$ for two-steps away partners. For household $i$ we compute $\mathbf{i v}_{6[i]} \equiv \sum_{j: g_{i j}^{0}=1}\left[\hat{\mathbf{G}}^{1} \mathbf{y}_{[j]}^{0}-\hat{\mathbf{G}}^{0} \mathbf{y}_{[j]}^{0}\right]$ summing over all $j$ who were connected to $i$ at baseline;

- $\mathbf{i v}_{7}$ represents the total expected increase in the number of two-steps away partners who got offered the savings account. For household $i$ we compute $\mathbf{i v}_{7[i]} \equiv \sum_{j: g_{i j}^{0}=1}\left[\hat{\mathbf{G}}^{1} \mathbf{i t t}_{[j]}-\hat{\mathbf{G}}^{0} \mathbf{i t t}_{[j]}\right]$ summing over all $j$ who were connected to $i$ at baseline.

These instruments combine the standard strategy of using exogenous lagged characteristics with the features of our data (two rounds of network data combined with a randomized household-level intervention). ${ }^{48}$

\subsection{Main Results}

We now present the main results. The dependent variable we consider for the empirical illustration is the household total non-food expenditure, in natural logs. The first- and second-stage estimates of the static network and the endogenous network models of peer effects are reported in Tables 7 and 8, respectively.

Table 7 shows the first-stage estimates for the peer-effect model with static network of equation (7) (column 1) and for the peer-effect model with endogenous network of

\footnotetext{
${ }^{48}$ Note that the construction of these instruments follows a logic of this kind: $\mathbf{i v}_{1}-\mathbf{i v}_{2}$ (which are meant to instrument the component $\Delta \mathbf{y}$ ) exploit the lagged partners' exogenous characteristics, $\mathbf{i v}_{3}-\mathbf{i} \mathbf{v}_{5}$ (which are meant to instrument the component $\Delta \mathbf{G}$ ) exploit the expected network change (we do not include $\hat{\mathbf{G}}^{0} \mathbf{i t t}$ as $\mathbf{G}^{0} \mathbf{i t t}$ enters directly as a regressor), and $\mathbf{i v}_{6}$ and $\mathbf{i v}_{7}$ (which are meant to instrument the product $\Delta \mathbf{G} \Delta \mathbf{y}$ ) combine the lagged partners' exogenous characteristics (as in $\mathbf{i v}_{1}-\mathbf{i} \mathbf{v}_{2}$ ) and the expected network change (as in $\left.\mathbf{i v}_{3}-\mathbf{i} \mathbf{v}_{5}\right)$. Since our dyadic model may generate many orthogonality conditions based on $\hat{\mathbf{G}}^{t}$ we have experimented with different sets of instruments. Results are generally consistent, but the power of the generated instruments may vary.
} 
equation (9) (columns $2-5$ ). The last line of Table 7 reports the weak identification tests. ${ }^{49}$

Table 8 reports five specifications: for the sake of comparison, we show in column (1) the estimates from a benchmark intent-to-treat model in first differences with no peer effects, which corresponds to the estimating equation $\Delta \mathbf{y}=\alpha \boldsymbol{\iota}+\gamma \mathbf{i t t}+\Delta \boldsymbol{\epsilon}$. Columns (2) and (3) report the estimates of the peer-effect model with static network of equation (7), via OLS and 2SLS, respectively. Columns (4) and (5) show the estimates of the peer-effect model with endogenous network of equation (9), via OLS and 2SLS, respectively.

The results are consistent across all specifications: while the direct intent-to-treat dummy does not seem to affect total non-food expenditure, ${ }^{50}$ the peer-effect terms $\mathbf{p e}_{A}$ and $\mathbf{p e}_{C}$ appear positive and statistically significant in all specifications. This is true whether we use OLS or the 2SLS instrumentation strategy. OLS estimated coefficients however, appear biased downwards. ${ }^{51}$ The estimated coefficient for $\mathbf{p e}_{A}$ in column (5) suggests that a $1 \%$ increase in the expenditure of baseline partners increases one's expenditure by $0.88 \%$. Interestingly, the peer-effect term $\mathbf{p e}_{C}$, which accounts for the interaction of the expenditure change and the network change, is also significant: getting new partners whose total expenditure increased 1\% more than the expenditure of old partners leads to an increase of $0.66 \%$ in one's expenditure.

Taken together, these results suggest that the increase of partners' expenditure, whether it comes from old partners (as reflected by $\mathbf{p e}_{A}$ ), or from new partners via the changes in the informal financial network (as reflected by $\mathbf{p} \mathbf{e}_{C}$ ), has a positive effect on one's expenditure. These results are in line with recent studies finding a positive peer effect for expenditure and social spending (Moretti 2011, Chen 2011, Brown, Bulte

\footnotetext{
${ }^{49}$ We run the Kleibergen-Paap F-test for column (1) and the Angrist-Pischke multivariate F-test for the remaining columns, where we have multiple endogenous regressors.

${ }^{50}$ This is in line with the results of Prina (2014) on the same data.

${ }^{51}$ This may suggest that unobservables correlated to link formation are negatively assorted within dyads, which may be the case for instance if low-expenditure households strategically link with high-expenditure ones.
} 
and Zhang 2011, De Giorgi, Frederiksen and Pistaferri 2012). On the other hand, the peer-effect term $\mathbf{p e}_{B}$ is not statistically significant: the baseline expenditure of new partners does not seem to have an effect per se on one's expenditure. Moreover, the other two regressors $\mathbf{G}^{0} \mathbf{i t t}$ and $\Delta \mathbf{G}$ itt are not statistically significant, suggesting that there is no direct effect of partners' treatment status once their expenditure is taken into account. Note that the variable $\mathbf{p e}_{C}$ has a positive mean (see Appendix Table A1), suggesting that those with the highest expenditure increase have also formed more new links.

Furthermore, also note that, for both OLS and 2SLS estimates, the coefficient associated with $\mathbf{p e}_{A}$ for the peer-effect model with static network is smaller than the corresponding coefficient for the peer-effect model with endogenous network. As $\mathbf{p e}_{A}$ and $\mathbf{p e}_{C}$ are negatively correlated in our sample, this suggests an omitted variable bias. Thus, in this context, not accounting for the network changes may generate peer-effect estimates that are biased downwards.

Finally, given that the direct and peer treatment status itt and $\mathbf{G}^{0} \mathbf{i t t}$ are never significant across Table 8, looking at results from the OLS and the static model (columns 1-3) one would conclude that total non-food expenditure is not affected by the randomized expansion in the access to savings accounts, but rather follows peers' behavior. However, our peer-effect model with endogenous network highlights a novel mechanism through which the intervention has an effect on expenditure by changing the household's network of informal financial transactions, as shown by the significance of the $\mathbf{p e}_{C}$ coefficient.

\section{Conclusions}

Networks might evolve in response to interventions. We first investigate whether this is the case, taking advantage of a field experiment that randomized access to a savings account, and using a unique panel data of the network of informal financial trans- 
actions before and after this exogenous expansion in formal financial access. Using household-level and dyadic regressions we provide evidence that the financial intervention changed the network. Then, we estimate a peer-effect model with endogenous network changes which incorporates the spillover effects of the intervention through the network. We show that the peer-effect estimates we obtain differ from those of the standard peer-effect model. In particular, in our context, not accounting for the network changes may generate peer effect estimates that are downward biased, and may disregard an important indirect channel through which the intervention affects household behavior.

By focusing on these previously unaccounted network changes our study provides novel insights on the way we should draw inference based on network data. One implicit assumption grounding all studies on networks and diffusion is that pre-existing relationships matter for economic outcomes, i.e. a better current network predicts better future outcomes. This assumption is indeed appropriate in a setting where the network is fixed, or hard to change. However, it is also possible that informal networks rewire easily in response to changes in the economic environment, and new links can be formed irrespective of pre-existing relationships. This might be the case when considering financial interventions, as we show in this study. Hence, more caution is recommended in interpreting pre-existing links in a causal manner, and in drawing policy recommendations based on that. ${ }^{52}$

\section{References}

Aportela, Fernando. 1999. "Effects of Financial Access on Savings by Low-Income People." Unpublished.

Arcand, Jean Louis, and Marcel Fafchamps. 2012. "Matching in CommunityBased Organizations." Journal of Development Economics, 98(2): 203-19.

Bandiera, Oriana, and Imran Rasul. 2006. "Social Networks and Technology Adoption in Northern Mozambique." Economic Journal, 116(514): 869-902.

\footnotetext{
${ }^{52} \mathrm{~A}$ similar argument is made by Comola and Fafchamps (2012) in the context of network formation.
} 
Banerjee, Abhijit V., Arun G. Chandrasekhar, Esther Duflo, and Matthew O. Jackson. 2013. "The Diffusion of Microfinance." Science, 341(6144): DOI: 10.1126/science.1236498

Banerjee, Abhijit V., Esther Duflo, Rachel Glennerster, and Cynthia Kinnan. Forthcoming. "The Miracle of Microfinance? Evidence from a Randomized Evaluation." American Economic Journal: Applied Economics.

Barr, Abigail, Marlene Dekker and Marcel Fafchamps. 2012. "Who Shares Risk with Whom under Different Enforcement Mechanisms?" Economic Development and Cultural Change, 60(4): 677-706.

Bertrand, Marianne, Erzo F. P. Luttmer, and Sendhil Mullainathan. 2000. "Network Effects and Welfare Cultures." The Quarterly Journal of Economics, 115(3): 1019-1055.

Binzel, Christine, Erica Field and Rohini Pande. 2013. "Does the Arrival of a Formal Financial Institution Alter Informal Sharing Arrangements? Experimental Evidence from Village India" Unpublished.

Bramoullé, Yann. 2013. "Comment." Journal of Business Economic and Statistics, 31(3): 264-266.

Bramoullé, Yann, Habiba Djebbari, and Bernard Fortin. 2009. "Identification of Peer Effects through Social Networks." Journal of Econometrics, 150(1): 41-55.

Brown, Philip, Erwin Bulte, and Xiaobo Zhang. 2011. "Positional Spending and Status Seeking in Rural China." Journal of Development Economics, 96(1): 139-149.

Bruhn, Miriam and Inessa Love. 2009. "The Economic Impact of Banking the Unbanked: Evidence from Mexico." World Bank Policy Research Working Paper 4981.

Brune, Lasse, Xavier Giné, Jessica Goldberg, and Dean Yang. 2011. "Commitments to Save: A Field Experiment in Rural Malawi." Unpublished.

Burgess, Robin and Rohini Pande. 2005. "Do Rural Banks Matter? Evidence from the Indian Social Banking Experiment." American Economic Review, 95: 780-795.

Cai, Jing, Alain de Janvry, and Elisabeth Sadoulet. Forthcoming. "Social Networks and the Decision to Insure: Evidence from Randomized Experiments in China." American Economic Journal: Applied Economics.

Calvó-Armengol, Antoni, Eleonora Patacchini, and Yves Zenou. 2009. "Peer Effects and Social Networks in Education." Review of Economic Studies, 76(4): 1239-1267.

Card, David and Laura Giuliano. Forthcoming. "Peer Effects and Multiple Equilibria in the Risky Behaviors of Friends." Review of Economics and Statistics.

Carvalho, Leandro, Silvia Prina, and Justin Sydnor. 2014. "The Effects of Savings on Risk Attitudes and Intertemporal Choices." Unpublished.

Chandrasekhar, Arun G., and Randall Lewis. 2011. "Econometrics of Sampled Networks." Unpublished.

Chen, Xi. 2011. "Accounting for Social Spending Escalation in Rural China," Leibniz Institute of Agricultural Development in Central and Eastern Europe (IAMO), 
Forum 2011.

Collins, Daryl, Jonathan Morduch, Stuart Rutherford, and Orlanda Ruthven. 2009. Portfolios of the Poor: How the World's Poor Live on 2 a Day. Princeton, NJ: Princeton University Press.

Comola, Margherita, and Marcel Fafchamps. 2010. "Are Gifts and Loans between Households Voluntary?" Paris School of Economics Working Paper 2010-19.

Comola, Margherita, and Marcel Fafchamps. Forthcoming. "Testing Unilateral and Bilateral Link Formation." The Economic Journal.

Conley, Timothy G., and Christopher R. Udry. 2010. "Learning about a New Technology: Pineapple in Ghana." American Economic Review, 100(1): 35-69.

Conning, Jonathan and Christopher Udry. 2007. "Rural Financial Markets in Developing Countries," in Handbook of Agricultural Economics, R. Evenson and P. Pingali (eds.), Volume 3, Chapter 56, 2857-2908. Elsevier, North-Holland.

De Giorgi, Giacomo, Anders Frederiksen and Luigi Pistaferri. 2012. "Consumption Networks Effects", unpublished.

De Weerdt, Joachim. 2004. "Risk Sharing and Endogenous Network Formation," in Insurance Against Poverty, Stephan Dercon (ed.), Oxford University Press.

De Weerdt, Joachim, and Marcel Fafchamps. 2011. "Social Identity and the Formation of Health Insurance Networks." Journal of Development Studies, 47(8): 1152-1177.

Di Falco, Salvatore, and Erwin Bulte. 2011. "A Dark Side of Social Capital? Kinship, Consumption, and Savings." Journal of Development Studies, 47(8): 1128-1151.

Drukker, David M., Peter Egger and Ingmar R. Prucha. 2013. "On Two-step Estimation of Spatial Autoregressive Models with Autoregressive Disturbances and Endogenous Regressors." Econometric Reviews, 32(5-6): 686-733.

Duflo, Esther, Michael Kremer, and Jonathan Robinson. 2008. "How High Are Rates of Return to Fertilizer? Evidence from Field Experiments in Kenya." American Economic Review, 98(2): 482-88.

Duflo, Esther, and Emmanuel Saez. 2003. "The Role of Information and Social Interactions in Retirement Plan Decisions: Evidence from a Randomized Experiment." The Quarterly Journal of Economics, 118(3): 815-842.

Dupas, Pascaline. 2014. "Short-Run Subsidies and Long-Run Adoption of New Health Products: Evidence from a Field Experiment." Econometrica, 82(1): 197-228.

Dupas, Pascaline, and Jonathan Robinson. 2013a. "Savings Constraints and Microenterprise Development: Evidence from a Field Experiment in Kenya." American Economic Journal: Applied Economics, 5(1): 163-192.

Dupas, Pascaline, and Jonathan Robinson. 2013b. "Why Don't the Poor Save More? Evidence from Health Savings Experiments." American Economic Review, 103(4): 1138-1171.

Ferrari, Aurora, Guillemette Jaffrin, and Sabin R. Shreshta. 2007. Access to Financial Services in Nepal. The World Bank, Washington, D.C. 
Fafchamps, Marcel, and Susan Lund. 2003. "Risk Sharing Networks in Rural Philippines." Journal of Development Economics, 71(2): 261-87.

Fafchamps, Marcel, and Simon Quinn. 2012. "Networks and Manufacturing Firms in Africa: Initial Results from a Randomised Experiment." Unpublished.

Feigenberg, Benjamin, Erica Field, and Rohini Pande. 2013. "The Economic Returns to Social Interaction: Experimental Evidence from Microfinance?" Review of Economic Studies, 80(4): 1459-1483.

Foster, Andrew D., and Mark R. Rosenzweig. 1995. "Learning by Doing and Learning from Others: Human Capital and Technical Change in Agriculture." Journal of Political Economy, 103(6): 1176-1209.

and Leeat Yariv. 2010. "Network Games." Review of Economic Studies, 77(1): $218-244$.

Goldsmith-Pinkham, Paul and Guido W. Imbens. 2013. "Social networks and the identification of peer effects." Journal of Business and Economic Statistics, 31(3): 253-264.

Graham, Bryan S. 2013. "Comment." Journal of Business Economic and Statistics, 31(3): 266-270.

Henrich, Joseph, Jean Ensminger, Richard McElreath, Abigail Barr, Clark Barrett, Alexander Bolyanatz, Juan Camilo Cardenas, Michael Gurven, Edwins Gwako, Natalie Henrich, Carolyn Lesorogol, Frank Marlowe, David Tracer, and John Ziker. 2010. "Markets, Religion, Community Size, and the Evolution of Fairness and Punishment." Science, 327(5972): 1480-1484.

Hoff, Karla, and Amartya Sen. 2006. "The Kin System as a Poverty Trap," in Poverty Traps, S. Bowles, S. Durlauf, and K. Hoff (eds.), Chapter 4, 95-115. Princeton University Press, Princeton.

Imberman, Scott, Adriana D. Kugler, and Bruce Sacerdote. 2009. "Katrina's Children: Evidence on the Structure of Peer Effects from Hurricane Evacuees." NBER Working Paper No. 15291, National Bureau of Economic Research.

International Monetary Fund. 2011. "Nepal Country Report No. 11/319." Asia and Pacific Department.

Jackson, Matthew O. 2008. Social and Economic Networks. Princeton, NJ: Princeton University Press.

Jackson, Matthew O. 2010. "An Overview of Social Networks and Economic Applications." in The Handbook of Social Economics, Jess Benhabib, Alberto Bisin, and Matthew Jackson (eds.), 511-586. North Holland Press 2011.

Jackson, Matthew O. 2013. "Unraveling Peers and Peer Effects: Comments on Goldsmith-Pinkham and Imbens' "Social Networks and the Identification of Peer Effects."' Unpublished.

Jackson, Matthew O. and L. Yariv (2010): "Diffusion, Strategic Interaction, and Social Structure," in The Handbook of Social Economics, Jess Benhabib, Alberto Bisin, and Matthew Jackson (eds.), 645-678. North Holland Press.

Jackson, Matthew O., and Allison Watts. 2002. "The Evolution of Social and 
Economic Networks." Journal of Economic Theory 106(2): 265-295.

Kaboski, Joseph P. and Robert M. Townsend. 2011. "A Structural Evaluation of a Large-scale Quasi-experimental Microfinance Initiative." Econometrica, 79: 1357-1406.

Karlan, Dean and Jonathan Zinman. 2010. "Expanding Credit Access: Using Randomized Supply Decisions to Estimate the Impacts." Review of Financial Studies, 23(1): 433-464.

Kast, Felipe, Stephan Meier, and Dina Pomeranz. 2011. "Under-savers Anonymous: Evidence on Self-help Groups and Peer Pressure as a Savings Commitment Device." NBER Working Paper No. 18417, National Bureau of Economic Research.

Kelejian, Harris H., and Gianfranco Piras. 2014. "Estimation of Spatial Models with Endogenous Weighting Matrices, and an Application to a Demand Model for Cigarettes." Regional Science and Urban Economics, 46: 140-149.

Kelejian, Harris H., and Ingmar R. Prucha. 1998. "A Generalized Spatial Two Stages Least Square Procedure for Estimating a Spatial Autoregressive Model with Autoregressive Disturbances." Journal of Real Estate Finance and Economics, 17(1): 99-121.

Kling, Jeffrey R., Jeffrey B. Liebman, and Lawrence F. Katz. 2007. "Experimental Analysis of Neighborhood Effects." Econometrica, 75(1): 83-119.

Kremer, Michael, and Dan Levy. 2008. "Peer Effects and Alcohol Use among College Students." Journal of Economic Perspectives, 22(3): 189-206.

Kremer, Michael, and Edward Miguel. 2007. "The Illusion of Sustainability." The Quarterly Journal of Economics, 122(3): 1007-1065.

Lee, Lung-Fei, Xiadong Liu and Xu Lin. 2010. "Specification and estimation of social interaction models with network structures," Econometrics Journal, 13, 145176.

Ligon, Ethan, Jonathan P. Thomas, and Tim Worrall. 2000. "Mutual Insurance, Individual Savings, and Limited Commitment." Review of Economic Dynamics 3(2): 216-246.

Liu, Xiaodong, Eleonora Patacchini, Yves Zenou, and Lung-Fei Lee, 2012. "Criminal Networks: Who is the Key Player?" Working Paper No. 2012.39, Fondazione Eni Enrico Mattei.

Manski, C., 1993 "Identification of Endogenous Social Effects: The Reflection Problem," Review of Economic Studies 60(3): 531-542.

Moretti, Enrico. 2011. "Social Learning and Peer Effects in Consumption: Evidence from Movie Sales," Review of Economic Studies, 78(1): 356-393.

Munshi, Kaivan. 2003. "Networks In The Modern Economy: Mexican Migrants In The U.S. Labor Market." The Quarterly Journal of Economics, 118(2): 549-599.

Munshi, Kaivan, 2004, "Social Learning in a Heterogeneous Population: Technology Diffusion in the Indian Green Revolution." Journal of Development Economics, 73(1): 185-213.

Nepal Rastra Bank. 2011. "Quarterly Economic Bulletin - Mid October 2011." 
Oaxaca, Ronald. 1973. "Male-female wages differentials in urban labor markets." International Economic Review 14(3): 693-709.

Oster, Emily, and Rebecca Thornton. 2012. "Determinants of Technology Adoption: Private Value and Peer Effects in Menstrual Cup Take-up." Journal of the European Economic Association, 10(6): 1263-1293.

Patacchini, Eleonora and Yves Zenou. 2012. "Juvenile Delinquency and Conformism." Journal of Law, Economics and Organization, 28(1): 1-31.

Patnam, Manasa. 2011. "Corporate Networks and Peer Effects in Firm Policies." Unpublished.

Platteau, Jean-Philippe. 2000. Institutions, Social Norms, and Economic Development. Amsterdam: Harwood Academic Publishers.

Prina, Silvia. 2014. "Banking the Poor via Savings Accounts: Evidence from a Field Experiment." Unpublished.

Watts, Allison. 2001. "A Dynamic Model of Network Formation." Games and Economic Behavior, 34(2): 331-341. 


\section{Figures and Tables}

Figure 1: Undirected binary network at baseline

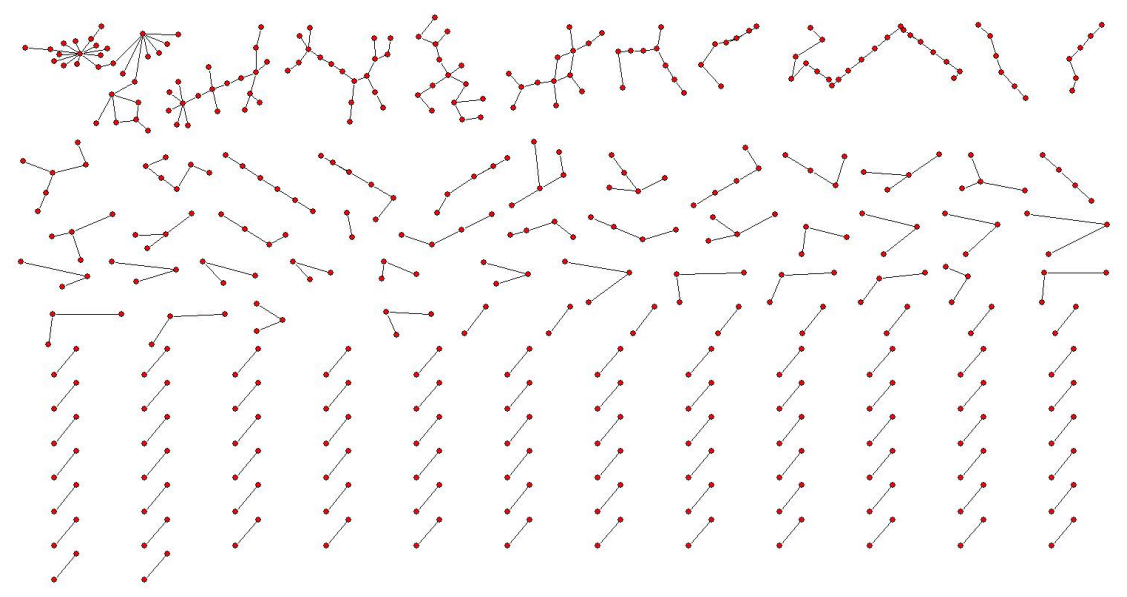

Figure 2: Undirected binary network at endline

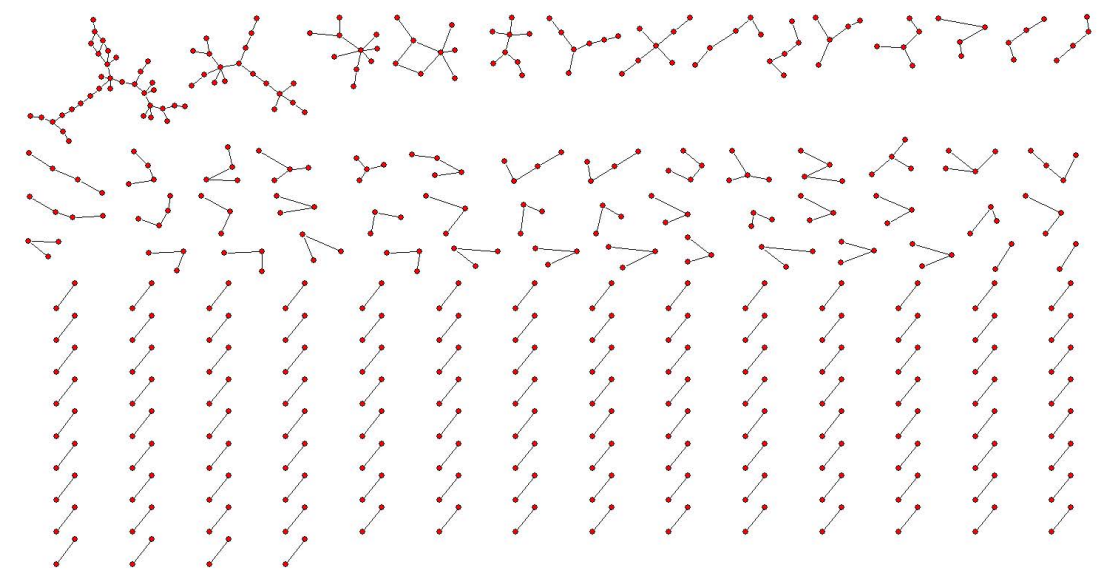


Table 1: Household Descriptive Statistics at Baseline

\begin{tabular}{|c|c|c|c|c|}
\hline & $\begin{array}{c}\text { Sample } \\
(\mathrm{N}=915)\end{array}$ & $\begin{array}{c}\text { Control } \\
(\mathrm{N}=447)\end{array}$ & $\begin{array}{c}\text { Treatment } \\
(\mathrm{N}=468)\end{array}$ & T-stat \\
\hline \multirow[t]{2}{*}{ Age of the female household head } & 36.80 & 36.77 & 36.82 & 0.05 \\
\hline & $(12.51)$ & $(12.16)$ & $(12.85)$ & \\
\hline \multirow[t]{2}{*}{ Years of education of the female household head } & 2.52 & 2.44 & 2.59 & 0.79 \\
\hline & $(2.82)$ & $(2.67)$ & $(2.96)$ & \\
\hline \multirow[t]{2}{*}{ Percent married/living with partner } & 0.89 & 0.88 & 0.90 & 0.77 \\
\hline & $(0.32)$ & $(0.33)$ & $(0.31)$ & \\
\hline \multirow[t]{2}{*}{ Household size } & 4.55 & 4.58 & 4.52 & -0.51 \\
\hline & $(1.66)$ & $(1.68)$ & $(1.64)$ & \\
\hline \multirow[t]{2}{*}{ Number of Children } & 2.21 & 2.26 & 2.18 & -0.86 \\
\hline & $(1.30)$ & $(1.30)$ & $(1.29)$ & \\
\hline \multirow[t]{2}{*}{ Total Income Last Week } & 1494.73 & 1472.84 & 1515.64 & 0.13 \\
\hline & $(4,833.91)$ & $(4,598.50)$ & $(5,053.36)$ & \\
\hline \multirow[t]{2}{*}{ Experienced a Negative Income shock } & 0.42 & 0.40 & 0.45 & $1.68^{*}$ \\
\hline & $(0.50)$ & $(0.49)$ & $(0.50)$ & \\
\hline \multirow[t]{2}{*}{ Total Assets } & 44469.26 & $42,510.10$ & 46340.51 & 1.14 \\
\hline & $(50,891.76)$ & $(45,540.07)$ & $(46,340.51)$ & \\
\hline \multirow[t]{2}{*}{ Percentage of Households with Money in a ROSCA } & 0.17 & 0.17 & 0.18 & 0.47 \\
\hline & $(0.38)$ & $(0.37)$ & $(0.38)$ & \\
\hline \multirow[t]{2}{*}{ Percentage of Households with Money in an MFI } & 0.56 & 0.58 & 0.54 & -1.25 \\
\hline & $(0.50)$ & $(0.49)$ & $(0.50)$ & \\
\hline \multirow[t]{2}{*}{ Percentage of Households with Money in a Bank } & 0.15 & 0.14 & 0.17 & 0.89 \\
\hline & $(0.36)$ & $(0.35)$ & $(0.37)$ & \\
\hline \multirow[t]{2}{*}{ Percentage of Households with Outstanding Loans } & 0.90 & 0.88 & 0.91 & 1.42 \\
\hline & $(0.31)$ & $(0.32)$ & $(0.29)$ & \\
\hline \multirow[t]{2}{*}{ n. of declared partners - total } & 1.42 & 1.39 & 1.45 & 0.61 \\
\hline & $(1.37)$ & $(1.35)$ & $(1.39)$ & \\
\hline \multirow[t]{2}{*}{ n. of declared partners - village } & 0.64 & 0.62 & 0.65 & 0.53 \\
\hline & $(0.92)$ & $(0.94)$ & $(0.89)$ & \\
\hline \multirow[t]{2}{*}{ n. of declared partners - out of village } & 0.79 & 0.77 & 0.80 & 0.32 \\
\hline & $(1.07)$ & $(1.02)$ & $(1.12)$ & \\
\hline \multirow[t]{2}{*}{ n. of gifts declared } & 0.79 & 0.72 & 0.86 & 1.32 \\
\hline & $(1.57)$ & $(1.47)$ & $(1.66)$ & \\
\hline \multirow[t]{2}{*}{ n. of loans declared } & 1.90 & 1.84 & 1.96 & 0.83 \\
\hline & $(2.12)$ & $(2.11)$ & $(2.13)$ & \\
\hline
\end{tabular}

Note: differences statistically significant at the $* 10 \%$, **5\%, or *** $1 \%$ level. 
Table 2: Attrition Regressions

\begin{tabular}{|c|c|c|c|}
\hline & \multicolumn{3}{|c|}{ Completed endline } \\
\hline & (1) & $(2)$ & $(3)$ \\
\hline \multirow[t]{2}{*}{$i t t$} & 0.009 & 0.008 & 0.008 \\
\hline & $(0.015)$ & $(0.015)$ & $(0.015)$ \\
\hline \multirow[t]{2}{*}{ n. of declared partners - total } & & -0.009 & \\
\hline & & $(0.015)$ & \\
\hline \multirow[t]{2}{*}{ n. of declared partners - village } & & & -0.001 \\
\hline & & & $(0.016)$ \\
\hline \multirow[t]{2}{*}{ n. of declared partners - out of village } & & & -0.010 \\
\hline & & & $(0.015)$ \\
\hline \multirow[t]{2}{*}{ n. of gifts declared } & & 0.002 & 0.001 \\
\hline & & $(0.004)$ & $(0.004)$ \\
\hline \multirow[t]{2}{*}{ n. of loans declared } & & 0.014 & 0.013 \\
\hline & & $(0.011)$ & $(0.011)$ \\
\hline \multirow[t]{2}{*}{ Constant } & $0.919^{* * *}$ & $0.914^{* * *}$ & $0.915^{* * *}$ \\
\hline & $(0.007)$ & $(0.009)$ & $(0.009)$ \\
\hline village dummies & yes & yes & yes \\
\hline Observations & 1,009 & 1,009 & 1,009 \\
\hline R-squared & 0.056 & 0.061 & 0.061 \\
\hline
\end{tabular}

Notes: Robust standard errors are in parentheses, clustered at the village level. Statistically significant coefficients are indicated as follows: $* 10 \%$, $* * 5 \%, * * * 1 \%$. All regressors are computed at $t=0$. itt represents the intent-to-treat dummy, which takes value one if the household was offered the savings account. 
Table 3: Household-level Intent-To-Treat Regressions

\begin{tabular}{|c|c|c|c|c|c|c|}
\hline & \multicolumn{3}{|c|}{$\begin{array}{l}\text { n. of partners within village } \\
\text { at endline }\end{array}$} & \multicolumn{3}{|c|}{$\begin{array}{l}\text { n. of partners outside village } \\
\text { (declared) at endline }\end{array}$} \\
\hline & (1) & $(2)$ & (3) & $(4)$ & $(5)$ & (6) \\
\hline \multirow[t]{2}{*}{$i t t$} & $0.1157^{* *}$ & $0.1018^{*}$ & $0.1052^{*}$ & -0.0490 & -0.0414 & -0.0460 \\
\hline & $(0.0499)$ & $(0.0561)$ & $(0.0530)$ & $(0.0701)$ & $(0.0676)$ & $(0.0689)$ \\
\hline \multirow[t]{2}{*}{ Constant } & $0.6600^{* * *}$ & $0.2325^{* * *}$ & 0.1816 & $0.5682^{* * *}$ & $0.8795^{* * *}$ & $0.8516^{* * *}$ \\
\hline & $(0.1021)$ & $(0.0249)$ & $(0.1486)$ & $(0.0792)$ & $(0.0300)$ & $(0.1073)$ \\
\hline Village dummies & no & yes & yes & no & yes & yes \\
\hline Controls & no & no & yes & no & no & yes \\
\hline Observations & 915 & 915 & 915 & 915 & 915 & 915 \\
\hline R-squared & 0.003 & 0.173 & 0.184 & 0.001 & 0.132 & 0.140 \\
\hline
\end{tabular}

Notes: this table reports the estimates of the household-level intent-to-treat regressions measuring the effect of the intervention on the intensity of network-based financial transactions. OLS coefficients reported. Robust standard errors in parentheses, clustered at the village level. Statistically significant coefficients are indicated as follows: * $10 \%, * * 5 \%, * * * 10 \%$. Controls at baseline include: age, no-education dummy, marital status, household size, number of children less than 16 years of age, shock dummies (death, livestock, land, harvest). itt represents the intent-to-treat dummy, which takes value one if the household was offered the savings account. 


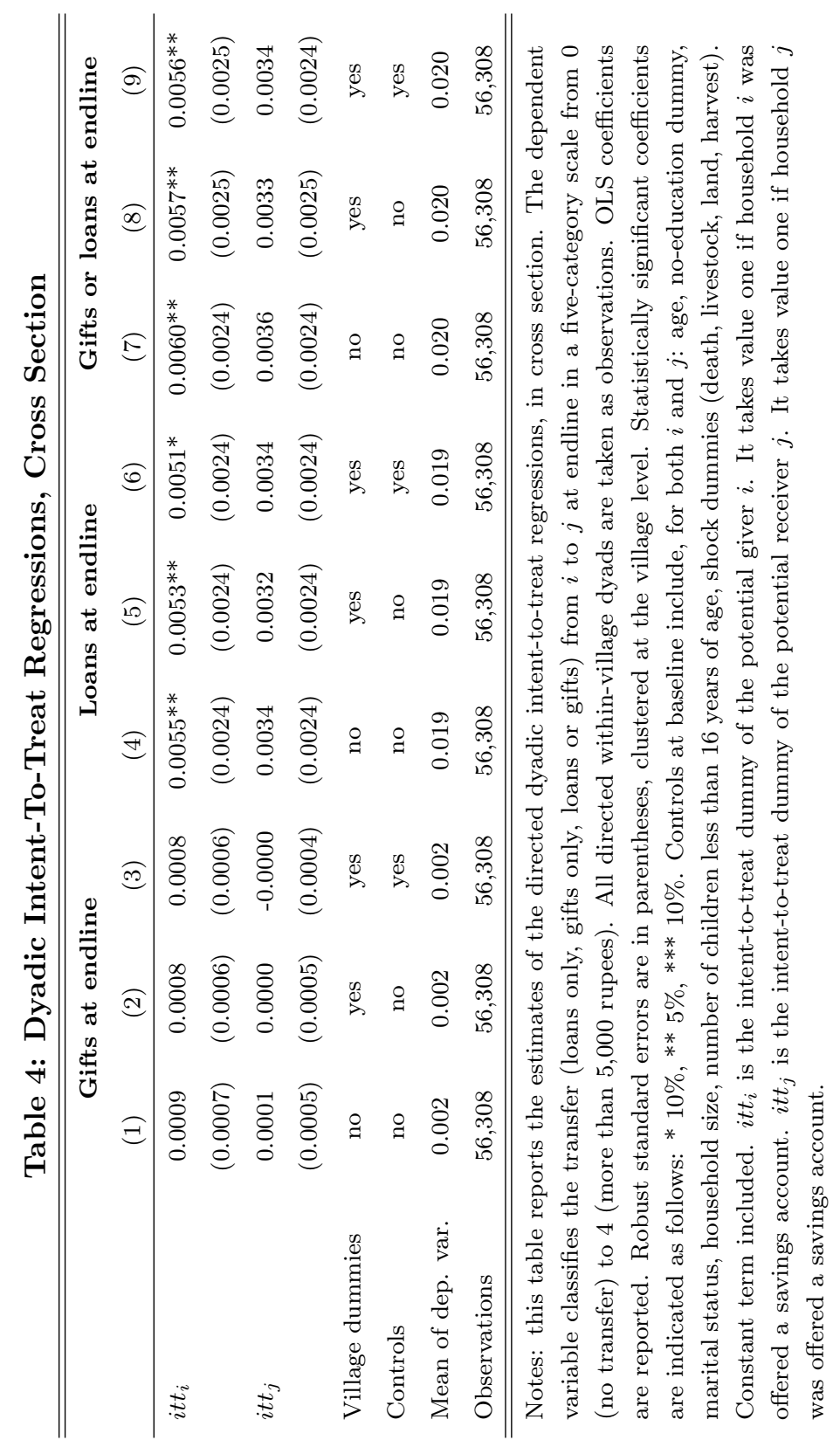




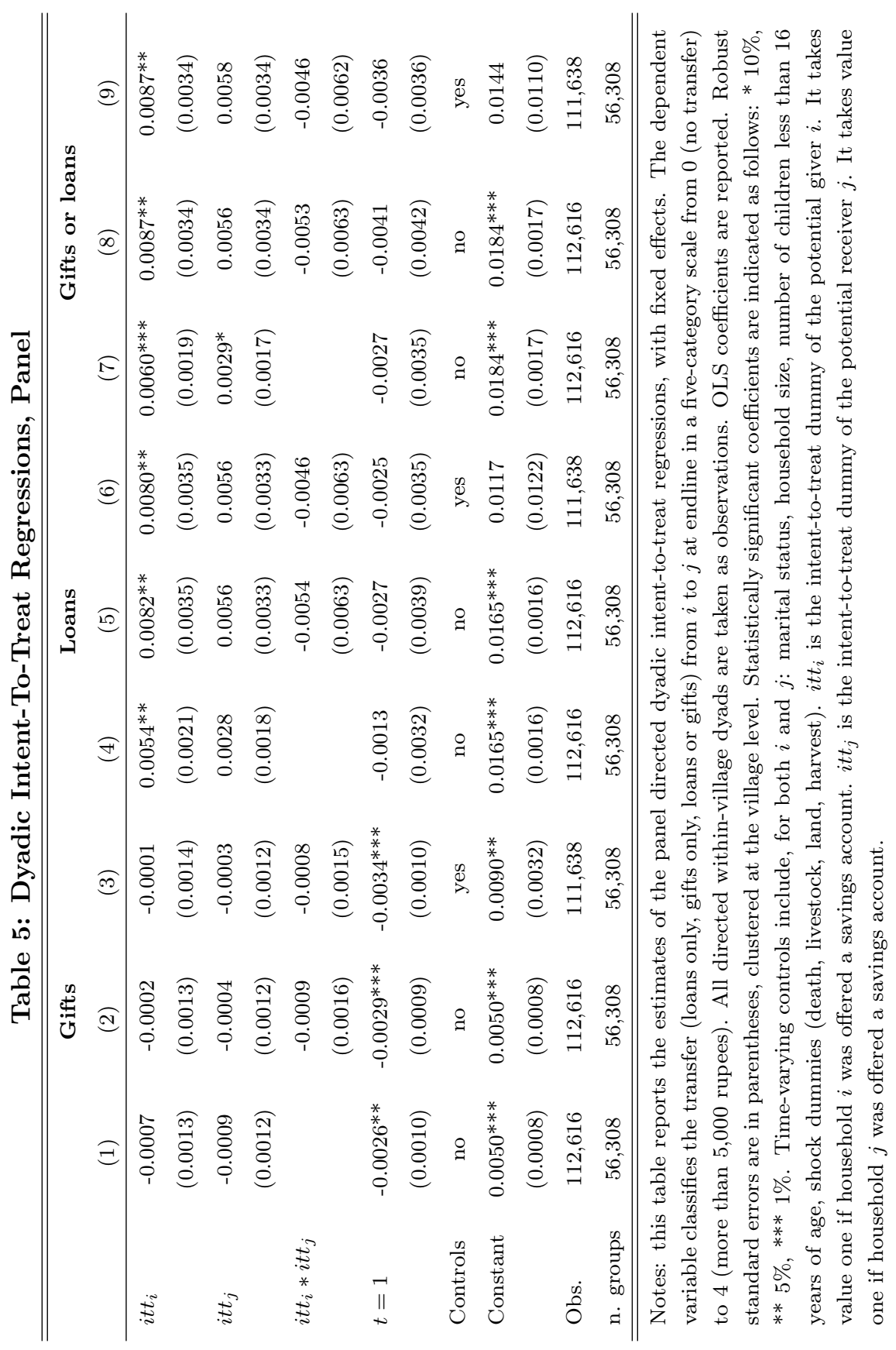


Table 6: Undirected Dyadic Regressions

\begin{tabular}{lcc}
\hline \hline & \multicolumn{2}{c}{ loans or gifts } \\
& $(1)$ & $(2)$ \\
\hline$i t t_{i}=1$ or $i t t_{j}=1$ & $0.0039^{*}$ & $0.0040^{* *}$ \\
& $(0.0023)$ & $(0.0020)$ \\
$i t t_{i}=1$ and $i t t_{j}=1$ & $0.0045^{*}$ & $0.0046^{* *}$ \\
& $(0.0022)$ & $(0.0023)$ \\
$t=1$ & -0.0031 & $-0.0031^{*}$ \\
& $(0.0023)$ & $(0.0017)$ \\
Controls & no & yes \\
Constant & $0.0117^{* * *}$ & $0.0188^{* * *}$ \\
& $(0.0010)$ & $(0.0062)$ \\
Obs. & 56,308 & 56,308 \\
n. groups & 28,154 & 28,154 \\
\hline \hline
\end{tabular}

Notes: this table reports the estimates of the panel undirected dyadic intent-to-treat regressions. The binary dependent variable takes value one if there is a transfer (loan or gift) between $i$ and $j$ at time $t$. OLS coefficients are reported. Robust standard errors are in parentheses, clustered at the village level. Statistically significant coefficients are indicated as follows: ${ }^{*} 10 \%, * * 5 \%, * * * 1 \%$. 
Table 7: Peer-effect Model, First Stage Regressions

\begin{tabular}{|c|c|c|c|c|c|}
\hline \multirow[b]{2}{*}{ Dependent var. } & \multirow{2}{*}{$\begin{array}{c}\text { Static Network } \\
\mathbf{p e}_{A} \\
(1)\end{array}$} & \multicolumn{4}{|c|}{ Endogenous Network } \\
\hline & & $\begin{array}{c}\mathbf{p e}_{A} \\
(2) \\
\end{array}$ & $\begin{array}{c}\mathbf{p e} \mathbf{e}_{B} \\
(3) \\
\end{array}$ & $\begin{array}{c}\mathbf{p e}_{C} \\
(4) \\
\end{array}$ & $\begin{array}{c}\Delta \mathrm{G} \text { itt } \\
(5)\end{array}$ \\
\hline \multirow[t]{2}{*}{ itt } & 0.051 & $0.368^{* *}$ & $0.998^{*}$ & $0.722^{* * *}$ & 0.093 \\
\hline & $(0.140)$ & $(0.169)$ & $(0.545)$ & $(0.209)$ & $(0.066)$ \\
\hline \multirow[t]{2}{*}{$\mathbf{G}^{0}$ itt } & -0.207 & -0.376 & $-5.763^{* * *}$ & 0.047 & $-0.724^{* * *}$ \\
\hline & $(0.534)$ & $(0.445)$ & $(0.917)$ & $(0.337)$ & $(0.059)$ \\
\hline \multirow[t]{2}{*}{$\mathbf{i v} \mathbf{v}_{1}$} & $0.233^{* * *}$ & $0.194^{* *}$ & 0.370 & $-0.205^{*}$ & 0.003 \\
\hline & $(0.086)$ & $(0.098)$ & $(0.382)$ & $(0.104)$ & $(0.020)$ \\
\hline \multirow[t]{2}{*}{$\operatorname{iv}_{2}$} & $-0.188^{* *}$ & $-0.142^{* *}$ & -0.148 & 0.083 & 0.003 \\
\hline & $(0.081)$ & $(0.062)$ & $(0.097)$ & $(0.055)$ & $(0.011)$ \\
\hline \multirow[t]{2}{*}{$\mathbf{i v}_{3}$} & & $-0.118^{*}$ & $-0.300^{*}$ & -0.096 & $-0.055^{* * *}$ \\
\hline & & $(0.061)$ & $(0.180)$ & $(0.102)$ & $(0.018)$ \\
\hline \multirow[t]{2}{*}{ iv $_{4}$} & & $-0.594^{* * *}$ & -0.383 & $-0.916^{* * *}$ & $-0.065^{*}$ \\
\hline & & $(0.071)$ & $(0.293)$ & $(0.223)$ & $(0.035)$ \\
\hline \multirow[t]{2}{*}{$\operatorname{iv}_{5}$} & & $9.700^{* * *}$ & $13.022^{* * *}$ & $11.954^{* * *}$ & $1.558^{* * *}$ \\
\hline & & $(0.848)$ & $(3.229)$ & $(3.318)$ & $(0.342)$ \\
\hline \multirow[t]{2}{*}{$\mathbf{i v}_{6}$} & & 0.007 & $5.112^{* * *}$ & -0.223 & -0.011 \\
\hline & & $(0.365)$ & $(1.259)$ & $(0.295)$ & $(0.023)$ \\
\hline \multirow[t]{2}{*}{$\operatorname{iv}_{7}$} & & 1.840 & $-60.247^{* *}$ & 5.209 & 0.348 \\
\hline & & $(5.822)$ & $(27.952)$ & $(4.663)$ & $(0.583)$ \\
\hline \multirow[t]{2}{*}{ Constant } & 0.221 & -0.238 & 1.190 & 0.488 & $0.221^{* * *}$ \\
\hline & $(0.196)$ & $(0.299)$ & $(1.047)$ & $(0.441)$ & $(0.079)$ \\
\hline Weak id. test $(P>F)$ & 0.041 & 0.030 & 0.000 & 0.039 & 0.074 \\
\hline
\end{tabular}

Notes: This table reports the first-stage estimates of the static network and endogenous network peer-effect models. The weak identification tests are the Kleibergen-Paap F-test for column (1) and the Angrist-Pischke multivariate F-test for the remaining columns. Robust standard errors are in parentheses, clustered at the village level. Statistically significant coefficients are indicated as follows: * $10 \%, * * 5 \%, * * * 1 \%$. The $i^{t h}$ subscript has been dropped for all vectors, i.e. itt reads $\operatorname{itt}_{[i]} \cdot \mathbf{p e}_{A} \equiv \mathbf{G}^{0} \Delta \mathbf{y}$ represents the change in partners' total expenditure keeping partners constant. $\mathbf{p e}_{B} \equiv \Delta \mathbf{G} \mathbf{y}^{0}$ represents the change in partners' total expenditure keeping expenditure constant. $\mathbf{p e}_{C} \equiv \Delta \mathbf{G} \Delta \mathbf{y}$ represent the interaction of the expenditure change and the network change. itt represents the intent-to-treat dummy, which takes value one if the household was offered the savings account. $\mathbf{G}^{0} \mathbf{i t t}$ represents the number of one's partners at baseline that was offered the savings account. $\Delta \mathbf{G}$ itt represents the change in the number of one's partners that was offered the savings account. 
Table 8: Peer-effect Model, Main Results

\begin{tabular}{|c|c|c|c|c|c|}
\hline & \multirow{2}{*}{$\begin{array}{c}\text { Benchmark } \\
\text { OLS }\end{array}$} & \multicolumn{2}{|c|}{ Static Network } & \multicolumn{2}{|c|}{ Endogenous Networl } \\
\hline & & OLS & 2SLS & OLS & 2SLS \\
\hline & (1) & $(2)$ & $(3)$ & (4) & (5) \\
\hline \multirow[t]{2}{*}{ itt } & -0.038 & -0.038 & -0.088 & -0.112 & -0.175 \\
\hline & $(0.132)$ & $(0.130)$ & $(0.175)$ & $(0.126)$ & $(0.301)$ \\
\hline \multirow[t]{2}{*}{$\mathbf{p e}_{A}$} & & $0.250^{* * *}$ & $0.844^{* * *}$ & $0.313^{* * *}$ & $0.877^{* * *}$ \\
\hline & & $(0.085)$ & $(0.219)$ & $(0.057)$ & $(0.302)$ \\
\hline \multirow[t]{2}{*}{$\mathbf{p e}_{B}$} & & & & 0.022 & 0.054 \\
\hline & & & & $(0.016)$ & $(0.045)$ \\
\hline \multirow[t]{2}{*}{$\mathbf{p e}_{C}$} & & & & $0.222^{* * *}$ & $0.659^{* *}$ \\
\hline & & & & $(0.019)$ & $(0.283)$ \\
\hline \multirow[t]{2}{*}{$\mathrm{G}^{0} \mathrm{itt}$} & & -0.139 & 0.125 & -0.016 & -0.617 \\
\hline & & $(0.127)$ & $(0.300)$ & $(0.138)$ & $(1.934)$ \\
\hline \multirow[t]{2}{*}{$\Delta \mathrm{G}$ itt } & & & & 0.002 & -1.371 \\
\hline & & & & $(0.211)$ & $(2.704)$ \\
\hline \multirow[t]{2}{*}{ Constant } & 0.279 & 0.351 & 0.329 & 0.207 & 0.269 \\
\hline & $(0.407)$ & $(0.378)$ & $(0.317)$ & $(0.321)$ & $(0.619)$ \\
\hline Observations & 915 & 915 & 915 & 915 & 915 \\
\hline R-squared & 0.000 & 0.062 & - & 0.160 & - \\
\hline
\end{tabular}

Notes: This table reports the estimates of a benchmark model with no peer effect, the static network and the endogenous network peer-effect models. Robust standard errors are in parentheses, clustered at the village level. Statistically significant coefficients are indicated as follows: $* 1 \%, * * 5 \%, * * * 1 \%$. The $i^{t h}$ subscript has been dropped for all vectors, i.e. itt reads itt $_{[i]}$. itt represents the intent-to-treat dummy, which takes value one if the household was offered the savings account. $\mathbf{p e}_{A} \equiv \mathbf{G}^{0} \Delta \mathbf{y}$ represents the change in partners' total expenditure keeping partners constant. $\mathbf{p e}_{B} \equiv \Delta \mathbf{G} \mathbf{y}^{0}$ represents the change in partners' total expenditure keeping expenditure constant. $\mathbf{p e}_{C} \equiv \Delta \mathbf{G} \Delta \mathbf{y}$ represent the interaction of the expenditure change and the network change. $\mathbf{G}^{0} \mathbf{i t t}$ represents the number of one's partners at baseline that was offered the savings account. $\Delta \mathbf{G}$ itt represents the change in the number of one's partners that was offered the savings account. 


\section{Appendix Tables}

Table A1: Descriptive Statistics for the Household Sample $(\mathrm{N}=915)$

\begin{tabular}{|c|c|c|c|c|c|}
\hline & $\mathbf{t}$ & Mean & Min & $\operatorname{Max}$ & Std. Dev. \\
\hline$i t t$ & - & 0.51 & 0 & 1 & 0.50 \\
\hline n. of partners within village & 1 & 0.72 & 0 & 7 & 1.00 \\
\hline n. of partners outside village $(\mathrm{decl})$ & 1 & 0.54 & 0 & 6 & 0.70 \\
\hline age & 0 & 36.80 & 16 & 99 & 12.51 \\
\hline no education & 0 & 0.34 & 0 & 1 & 0.48 \\
\hline married & 0 & 0.89 & 0 & 1 & 0.32 \\
\hline single & 0 & 0.01 & 0 & 1 & 0.11 \\
\hline n. children $<16$ & 0 & 1.97 & 0 & 7 & 1.25 \\
\hline HH members & 0 & 4.55 & 1 & 12 & 1.66 \\
\hline shock: death & 0 & 0.01 & 0 & 1 & 0.11 \\
\hline shock: livestock loss & 0 & 0.09 & 0 & 1 & 0.29 \\
\hline shock: land loss & 0 & 0.01 & 0 & 1 & 0.07 \\
\hline shock: bad harvest & 0 & 0.02 & 0 & 1 & 0.13 \\
\hline$\Delta y$ & - & 0.26 & -9.82 & 10.01 & 2.61 \\
\hline $\mathbf{p e}_{A}$ & - & -0.08 & -15.53 & 21.78 & 2.53 \\
\hline $\mathbf{p e}_{B}$ & - & -0.46 & -89.91 & 30.20 & 9.20 \\
\hline $\mathbf{p e}_{C}$ & - & 0.68 & -12.21 & 44.39 & 3.71 \\
\hline $\mathrm{G}^{0} \mathrm{itt}$ & - & 0.36 & 0 & 9 & 0.70 \\
\hline$\Delta \mathrm{G}$ itt & - & 0.03 & -5 & 4 & 0.83 \\
\hline IV 1 & - & 0.49 & 0 & 10 & 1.40 \\
\hline IV 2 & - & 1.96 & 0 & 11.36 & 3.47 \\
\hline IV 3 & - & 5.21 & 0.99 & 13.66 & 2.44 \\
\hline IV 4 & - & 5.18 & 0.85 & 12.92 & 2.54 \\
\hline IV 5 & - & 0.41 & 0.04 & 0.92 & 0.18 \\
\hline IV 6 & - & -0.05 & -5.37 & 5.28 & 0.73 \\
\hline IV 7 & - & 0.02 & -0.18 & 0.53 & 0.06 \\
\hline
\end{tabular}


Table A2: Descriptive Statistics for the Dyadic Sample $(N=56,308)$

\begin{tabular}{|c|c|c|c|c|c|}
\hline & $\mathrm{t}$ & Mean & Min & $\operatorname{Max}$ & Std. Dev. \\
\hline loans, cat. & 0 & 0.005 & 0 & 4 & 0.094 \\
\hline gifts, cat. & 0 & 0.016 & 0 & 4 & 0.211 \\
\hline loans or gifts, cat. & 0 & 0.018 & 0 & 4 & 0.220 \\
\hline loans, cat. & 1 & 0.002 & 0 & 4 & 0.058 \\
\hline gifts, cat. & 1 & 0.019 & 0 & 4 & 0.257 \\
\hline loans or gifts, cat. & 1 & 0.020 & 0 & 4 & 0.260 \\
\hline loans or gifts, bin. undir. & 0 & 0.012 & 0 & 1 & 0.107 \\
\hline loans or gifts, bin. undir. & 1 & 0.012 & 0 & 1 & 0.107 \\
\hline age & 0 & 37.396 & 16 & 99 & 13.186 \\
\hline no education & 0 & 0.324 & 0 & 1 & 0.468 \\
\hline married & 0 & 0.885 & 0 & 1 & 0.319 \\
\hline single & 0 & 0.012 & 0 & 1 & 0.108 \\
\hline n. children $<16$ & 0 & 1.935 & 0 & 7 & 1.246 \\
\hline HH members & 0 & 4.511 & 1 & 12 & 1.675 \\
\hline shock: death & 0 & 0.012 & 0 & 1 & 0.107 \\
\hline shock: livestock loss & 0 & 0.081 & 0 & 1 & 0.273 \\
\hline shock: land loss & 0 & 0.005 & 0 & 1 & 0.070 \\
\hline shock: bad harvest & 0 & 0.015 & 0 & 1 & 0.120 \\
\hline married & 1 & 0.853 & 0 & 1 & 0.354 \\
\hline single & 1 & 0.010 & 0 & 1 & 0.100 \\
\hline n. children $<16$ & 1 & 1.457 & 0 & 6 & 1.202 \\
\hline HH members & 1 & 4.486 & 1 & 16 & 1.734 \\
\hline shock: death & 1 & 0.006 & 0 & 1 & 0.078 \\
\hline shock: livestock & 1 & 0.021 & 0 & 1 & 0.143 \\
\hline shock: land & 1 & 0.000 & 0 & 0 & 0.000 \\
\hline shock: harvest & 1 & 0.000 & 0 & 0 & 0.000 \\
\hline
\end{tabular}

